\title{
De las edades del Cobre y el Bronce, de investigaciones y de mujeres en Castilla y León.
}

\section{About Copper and Bronze Ages, researches and women in Castilla and Leon}

\author{
Antonio Bellido Blanco. \\ Museo de Valladolid \\ A la memoria de $M^{a}$ Dolores Fernández-Posse
}

Recibido: 21-12-2012

Aceptado: 07-10-2013

\section{Resumen}

El presente trabajo parte de comprender el papel que las investigadoras han jugado en el estudio de las Edades del Cobre y el Bronce de la Meseta Norte frente a sus colegas varones. Pero además se profundiza en el alcance que hasta la actualidad tiene el conocimiento de la vida de las mujeres prehistóricas en el ámbito mencionado, dejando entrever lagunas, contradicciones y las muchas posibilidades que aún quedan por desarrollar.

Palabras clave: Feminismo, Arqueología del Género, Meseta Norte, Edad del Bronce, Calcolítico.

\begin{abstract}
This work begins with the attempt of understand the part played by the women researchers in the study of Copper and Bronze Ages of Spanish Northern Plateau. Furthermore it goes more deeply into the current knowledge of prehistoric women within that field of investigation, suggesting gaps, contradictions and numerous possibilities still to development.
\end{abstract}

Keywords: Feminism, Gender Archaeology, Northern Plateau, Bronze Age, Chalcolithic.

\section{Feminismo}

Cuando se revisan las antiguas fotografías de los estudiantes universitarios, uno se encuentra desde hace décadas con la presencia de mujeres. Las referencias no abundan, pero más allá de las listas de alumnos o de fotos de excursiones culturales, el Boletín del Seminario de Arte y Arqueología de la Universidad de Valladolid ofrece una muestra sumamente ilustrativa (fig. 1). Dentro de su Plan de Trabajos para el curso 1932/33 participan once varones y doce mujeres, y en el curso siguiente aumentan a dieciséis varones y diecisiete mujeres, ocupados en estudios que abarcan variados temas de prehistoria, arqueología, arte, archivística e incluso folklore (Mergelina, 1932-33, 1933-34). Bien es cierto que el cuadro de profesores se componía sólo de varones; y así habría de continuar durante mucho tiempo, por más que entre los "ayudantes-colaboradores" del curso 1935/36 se incluya a Concepción Álvarez Terán y a Mercedes González Tejerina, más orientadas hacia los estudios de arte y archivística que hacia la arqueología. 
Como puede intuirse, el conocido como "techo de cristal" lleva mucho tiempo presente en la realidad universitaria española, pero no queremos abarcar demasiado en este trabajo. Nuestra intención es centrarnos en analizar la presencia de las investigadoras en los estudios relativos a la Edad del Cobre y del Bronce de la Meseta Norte, que resulta algo posterior a aquellos años, así como recoger las consideraciones que han merecido las mujeres dentro de las interpretaciones elaboradas sobre esos periodos de la Prehistoria.

\subsection{UN MUNDO MASCULINO}

Los estudios de la Prehistoria en la Meseta Norte estuvieron en principio a remolque de lo que desde las universidades madrileña y barcelonesa se establecía para la evolución de toda la Península Ibérica. Pocos eran los yacimientos conocidos y de éstos apenas se llegaba a reseñar más que unos pequeños lotes de materiales cerámicos y algunos hallazgos aislados y depósitos de metales. Los poblados identificados en tierras burgalesas por Martínez Santa-Olalla, en Soria

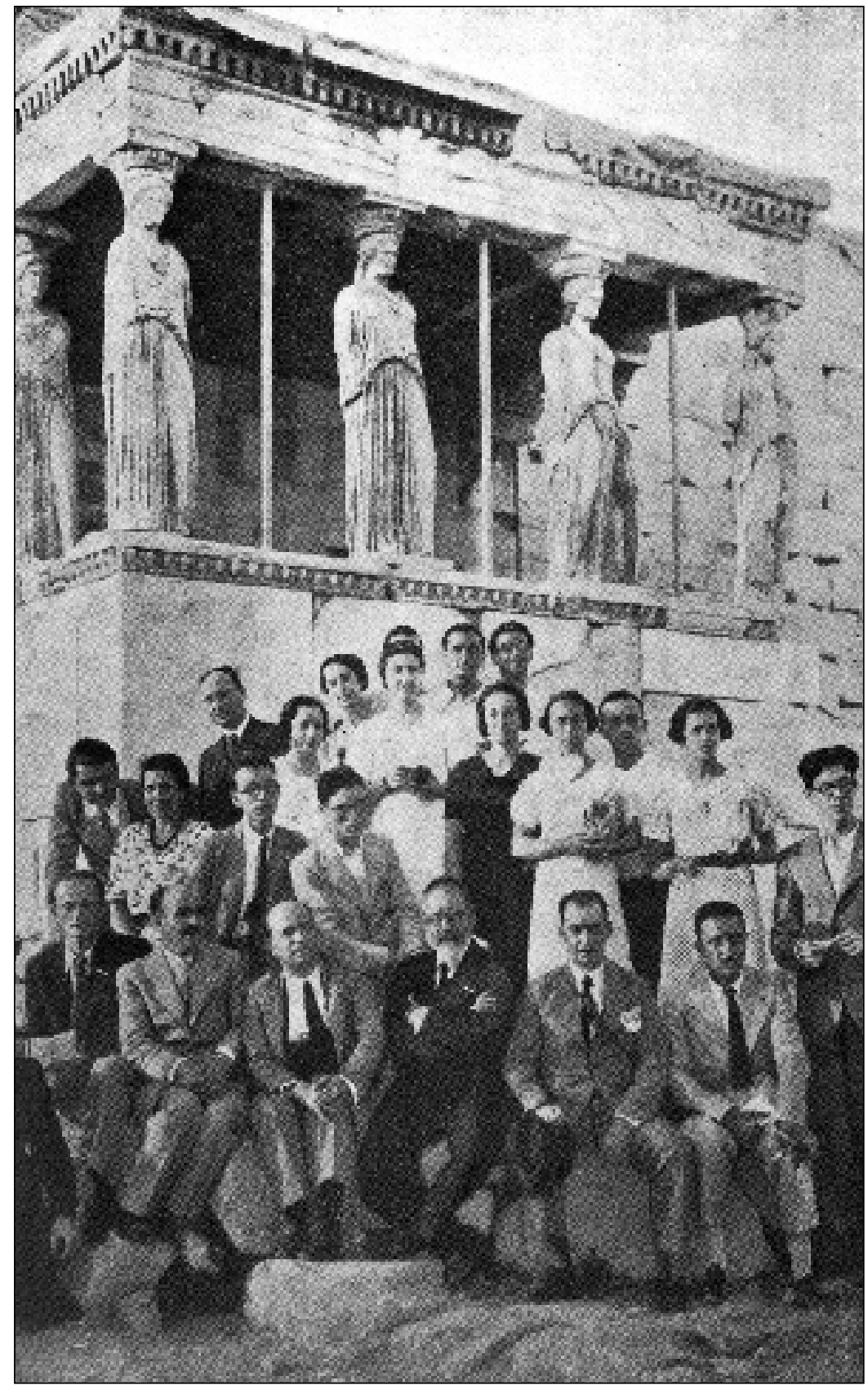

Figura 1. Estudiantes del Seminario de Arte y Arqueología de la Universidad de Valladolid en la Acrópolis de Atenas durante el viaje de estudios a Grecia en 1933. 
por Blas Taracena, en Salamanca y Zamora por el padre César Morán o en la Tierra de Campos por Eugenio Merino apenas dan más luz al conocimiento de esta fase de la Prehistoria. Acaso lo más destacado resulten las excavaciones de Juan Cabré (1930) en el Castro de Las Cogotas (Ávila) y las del padre Morán en el cerro del Berrueco y en los dólmenes salmantinos y zamoranos.

El esquema histórico trazado en estos momentos, basado en culturas monolíticas que se expanden y son reemplazadas por otras nuevas, se mantiene casi inalterado durante las siguientes décadas. Ahí están los trabajos de Pere Bosch Gimpera (1923) y Luis Pericot (1923) en los años veinte, donde se aprecia con claridad cómo entre el final del Neolítico y el inicio de la Edad del Bronce se reconocía una denominada Cultura de Almería bien definida en el levante y sureste español, mientras para el área septentrional se identifica una cultura pirenaica y para el occidente una cultura portuguesa. Al mismo tiempo las tierras del interior seguirían ocupadas por una población de tradición capsiense, denominada cultura central o de las cuevas, enraizada en el Paleolítico. Con la Edad del Bronce, la cultura almeriense trueca en argárica y llega a imponerse en el conjunto de la Península. En el manual "La España primitiva", que Luis Pericot publicó en 1950, lo único que se destaca para la caracterización de las tierras del interior peninsular son las numerosas evidencias de vasos campaniformes, que llegarían desde Andalucía oriental (Pericot, 1950: 160-3).

Como vemos en este rosario de nombres, se cumple la premisa puesta de manifiesto por Margarita Díaz-Andreu (1998a: 125) de que las mujeres están ausentes en la Arqueología española de la mayor parte del siglo XX. Las provincias de Castilla y León no son una excepción a esa norma. Tan sólo pueden mencionarse a la zamorana Ursicina Martínez Gallego (Fernández 2005), que aprobó las oposiciones del Cuerpo Facultativo de Archiveros, Bibliotecarios y Arqueólogos en 1930 y dirigió el Museo Arqueológico de León desde el año siguiente y hasta 1941 (sus predecesores en el cargo durante los seis años anteriores a su llegada fueron también mujeres: Pilar Corrales y Teresa Andrés), y Pilar Fernández Vega, perteneciente al mismo cuerpo desde 1922 y que tuvo un fugaz paso por el Museo Arqueológico de Valladolid durante la Guerra Civil (el resto de su carrera la desarrolló en Madrid) (Díaz-Andreu, 1998a; Díaz Andreu et al., 2009: 421). Ninguna de las dos se dedicó a la investigación prehistórica; y mientras la primera volvió a su tierra y alumbró algunas publicaciones desde su puesto en la Biblioteca Pública de Zamora, la segunda se centró en temas de arqueología precolombina, en especial tras su nombramiento como directora del Museo de América en 1941.

Así mismo la creación del Seminario de Estudios de Arte y Arqueología en la Universidad de Valladolid en 1932 nos permite reconocer a unas pocas mujeres que abordan estudios sobre la Prehistoria, como Casilda Solano, si bien su actividad se difumina ante el predominio de sus compañeros varones. El tema que eligió para su trabajo de curso, las fíbulas prerromanas del Museo Arqueológico de Valladolid, pasó en 1933 a Julio Barrientos (dejando ella de aparecer mencionada en las actividades del Seminario); a la vez que éste y Carlos Serrano acaparan todos los proyectos del Seminario relativos a la Prehistoria durante los años de la II República (Bellido, 2008: 467-8).

La presencia de Socorro González de Madrid en la dirección del Museo Arqueológico de Valladolid entre 1959 y 1974 tampoco cambia este panorama en absoluto. De hecho durante estos años lo que más se suele destacar en los estudios historiográficos es el paso por el museo de Federico Wattenberg, que tuvo un papel básico en la configuración de la reforma del museo, que se inaugura en 1968 en su actual emplazamiento del palacio de Fabio Nelli (Wattenberg, 2000: 415). También cabe mencionar que era esposa de Filemón Arribas, director del Archivo Histórico Provincial de Valladolid, catedrático de la Universidad de Valladolid y con una destacada implicación política durante el franquismo.

Como puede apreciarse, el dominio masculino es absoluto. Y el cambio que comienza a gestarse desde el punto de vista regional con un mayor peso de investigadores que intensifican los trabajos locales, cuyos primeros exponentes son a partir de 1949 las actividades de Federico Wattenberg Sampere, en Valladolid, y Juan Maluquer de Motes, en Salamanca, no tiene parangón en el ámbito de sus colegas mujeres. 
En el cuadro de profesores de Arqueología en las universidades de Valladolid y Salamanca, la ausencia de mujeres es continua en los años cuarenta y cincuenta. Margarita Díaz Andréu (1998: 133) ha señalado cómo muchas estudiantes de aquellos años veían sus estudios universitarios tan sólo como una preparación y un poso cultural para su futura vida como esposas y madres, pero también ha indicado las dificultades que se les planteaban para trabajar en este ámbito una vez que se casaban. Tan sólo se ve que van cobrando mayor importancia las universidades regionales en las tareas investigadoras mientras eruditos y sacerdotes, que hasta entonces habían jugado un papel relevante en las Comisiones Provinciales, desaparecen del panorama. Wattenberg, vinculado con la escuela madrileña a través de su maestro Cayetano de Mergelina, se centró en el estudio de la Edad del Hierro, si bien es de destacar su trabajo sobre los hoyos "neoeneolíticos" de Villabrágima (Wattenberg, 1949). Juan Maluquer, discípulo de Luis Pericot en la escuela barcelonesa y catedrático de la universidad salmantina, estuvo mucho más metido en estudios relativos a la Edad del Bronce ( $v d$. Maluquer, 1960).

La Universidad de Valladolid comienza a ampliar su plantilla en los años sesenta y a la sombra del catedrático Pedro de Palol se incorporan jóvenes investigadores, como Ricardo Martín Valls, pero la presencia femenina sigue siendo esporádica más allá del alumnado. Carmen Trapote Sinovas es una de las discípulas de Pedro de Palol y publica un par de trabajos en 1964 sobre arqueología romana, sin embargo luego aparca esta especialización para dedicarse más a temas de Historia del Arte e Historia Moderna. De hecho en los años sesenta trabajó con Palol en Clunia, la villa romana de Dueñas y en el Soto de Medinilla y aún en 1983 dirigió una excavación arqueológica en la catedral de Palencia; sin embargo su dedicación principal fue la Escuela de Arte de Palencia, a la que se dedicó desde 1965 (VV.AA., 2008). Poco después, en 1967, encontramos a Carmen García Merino, dedicada igualmente al mundo romano, que sí lograría formar parte del profesorado de la Universidad de Valladolid. En Salamanca el panorama universitario es similar en esos años, con algunos estudios de arqueología romana realizados por Agapita Serrano y Dulce Estefanía que ven la luz en Zephyrus entre 1957 y 1960 (si bien no son investigadoras salmantinas). El único trabajo relativo a la prehistoria de la Meseta Norte realizado por una mujer en estos años es el que desarrolla Vera Leisner sobre el megalitismo en Ciudad Rodrigo (Leisner y Schubart, 1964).

\section{2. LA RENOVACIÓN DE LOS AÑOS SETENTA}

Una nueva generación de arqueólogos llega a las universidades en los años setenta. Son años de reformas universitarias, con contratación de mucho personal, lo que permitió a muchos jóvenes licenciados incorporarse a las plantillas de docentes y desarrollar sus investigaciones. Entre sus preocupaciones destaca la necesidad de llenar los numerosos vacíos existentes en el conocimiento de la prehistoria meseteña. Las primeras investigadoras que empiezan a publicar encuentran su tema de especialización en el Paleolítico, como ocurre con Soledad Corchón y Mercedes Cano. Dentro del periodo prehistórico que nos interesa, algunos de los temas abordados son la extensión del megalitismo, precisiones cronológicas y, en la cultura material, caracterizaciones y tipologías. Pero además para profundizar en ellos se acomete un número creciente de intervenciones arqueológicas.

Si se repasan los trabajos de estos años destaca, por un lado, la polarización de la atención en los estudios de la cerámica y su clasificación tipológica. Esto no resulta infrecuente entonces y así el predominio de este tipo de estudios normativistas, en los que la ordenación de determinados conjuntos de elementos de cultura material era equiparada a la delimitación de culturas arqueológicas, es la pauta que siguen muchos jóvenes licenciados al abordar sus tesis doctorales. Así proceden, por ejemplo, Germán Delibes (1977) o Julio Fernández Manzano (1986) -éste para el caso de los metales- y otros que estudian yacimientos concretos como Jorge Juan Eiroa (1979) o Alfredo Jimeno (1984). Entre sus colegas femeninas ocupadas en este ámbito de la prehistoria parece predominar la elección del tema de la cerámica.

El historicismo cultural predominante aún en esos años se manifiesta claramente en Germán Delibes y sus estudios sobre la cerámica de boquique y excisión. Una de sus aportaciones reside en invalidar la asimilación de las cerámi- 
cas excisas con gentes indoeuropeas a partir de la consideración de diversos testimonios de inhumaciones entre las gentes de Cogotas I. Sin embargo, por más que incida en la importancia de la población indígena en el desarrollo de esta tradición funeraria (también peninsular sería la técnica de boquique, como habían expuesto Molina y Arteaga 1976), no puede rechazar que la génesis de la técnica de la excisión se hubo de producir en algún lugar concreto de Europa desde donde se extendería al resto de zonas como una moda generalizada entre grupos pastores (Delibes, 1978: 237-44).

$\mathrm{M}^{\mathrm{a}}$ Dolores Fernández-Posse, aun incluyéndose dentro de la misma corriente investigadora, aporta matices que ofrecen un cambio sustancial en la consideración de las culturas caracterizadas por los elementos de cultura material. Ya en su primer trabajo muestra la existencia de continuidades entre lo que entonces se consideran culturas sucesivas que se desarrollan en un mismo lugar. Así es como recalca la presencia de vasijas que mantienen sus formas en el yacimiento de la cueva de Arevalillo y sólo se van modificando de forma paulatina desde el Campaniforme al Bronce Final, mientras que sobre esta base se incorpora en un determinado momento la técnica del boquique, que a su vez también va evolucionando en sus diseños compositivos con el paso del tiempo (FernándezPosse, 1979: 81-3; 1981: 70-80). Aún más, observa que la llegada del campaniforme (caracterizado tanto por sus cerámicas como por el rito de enterramiento y la generalización de la metalurgia) no supone un cambio sustancial en la evolución de las gentes indígenas (FernándezPosse, 1979: 82). Pero sus aportaciones no acaban aquí, puesto que también introduce consideraciones relativas a la funcionalidad de las vasijas cuando expresa la compatibilidad de los tipos campaniformes "Silos" y "Molino", ambos propios del oriente de la Meseta. Deudores de los grupos que había definido décadas antes Alberto del Castillo, se habían interpretado inicialmente los rasgos propios de estos tipos con un valor cronológico de modernidad frente al resto de estilos localizados en la Meseta Norte hasta que Delibes y Municio (1981) los asimilaron a Ciempozuelos. Fernández-Posse (1981: 69), por su parte, obvió estas cuestiones temporales para destacar cómo la diferenciación del tipo Molino vendría dada por incluir grandes vasijas de uso exclusivo en lugares de habitación que quedaban excluidas de los contextos funerarios.

Otros estudios tipológicos surgen de la mano de autoras como Candelas Naranjo González, quien tiene una aparición relativamente fugaz en este campo, no carente de importancia, que se reduce a su memoria de Licenciatura. Ésta se dedica a la cultura material del yacimiento del Castillo de Cardeñosa (Naranjo, 1984) y no resulta demasiado diferente de trabajos contemporáneos de colegas varones como Eiroa o Jimeno. El trabajo fue presentado en octubre de 1981 en la Universidad Complutense y su director fue Martín Almagro Basch. Con posterioridad sólo tenemos constancia de su dedicación a diversos estudios de genealogía y archivística relativos a la historia moderna y contemporánea, publicados durante la última década.

María Teresa Mínguez Álvaro realiza sus primeras investigaciones al comienzo de los años ochenta, si bien después pasa un largo periodo sin publicaciones hasta la lectura de su tesis doctoral en 2001. Pese a ser una obra reciente, el tiempo transcurrido desde su época de formación hace que la encuadremos en este grupo generacional. Su principal contribución ha sido el estudio de la cerámica del Bronce Final del yacimiento de Cueva Mayor, en Atapuerca (Burgos) (Mínguez, 2005a, 2005b), para el que adopta un enfoque manifiestamente normativista y donde sigue planteamientos teóricos que parten de los trabajos sobre atribución de autoría iniciados por Apellániz en los años setenta, unidos a enfoques etnoarqueológicos, como ha puesto en evidencia Antonio Blanco (2005).

En el estudio del Calcolítico y el Megalitismo se ha venido centrando Socorro López Plaza, de la Universidad de Salamanca. Su encuadre teórico la condujo inicialmente a los análisis tipológicos de las cerámicas (López Plaza, 1975, 1979), como varias de las anteriores autoras, y de las armas de cobre (López y Santos, 198485), pero ha contemplado también el estudio de las manifestaciones de arte rupestre (López, 1983, 1999; Sevillano et al., 1996). A partir de los años noventa, influenciada por los trabajos de Arqueología del Paisaje que se realizan desde Galicia, compagina textos que continúan en la línea anterior con otros sobre la influencia de la astronomía en la orientación de los sepulcros megalíticos y la relación de éstos con la articula- 
ción del territorio y las vías de comunicación (López et al., 1991-92 y 2000, Senna-Martínez et al., 1997). Más recientemente ha desarrollado esta tendencia en un trabajo sobre la procedencia de los bloques pétreos usados en varios dólmenes salmantinos, que la propia autora vincula con el post-procesualismo (López et al., 2008).

Todo esto nos lleva a otro de los centros de atención de la investigación prehistórica, el de las manifestaciones de arte rupestre, donde han destacado varias mujeres junto a colegas como el soriano Juan Antonio Gómez Barrera. María Rosario Lucas Pellicer, desde la Universidad Autónoma de Madrid, dedicó el grueso de su trabajo al arte rupestre de la provincia de Segovia. Unos inicios volcados sobre todo en la recogida e inventario de estas muestras artísticas (Lucas, 1971, 1974, 1975), dieron paso a enfoques procesuales preocupados por el establecimiento de leyes generales y por los cambios producidos a lo largo del tiempo (Lucas, 1981, 1989, 1992; Lucas y Castelo, 1992, Cardito et al., 1997). Sin embargo, desde 1990 elaboró estudios que incidían especialmente en los aspectos mágicos y transcendentes de las representaciones, con lo cual se aprecia una mayor voluntad interpretativa que la llevó al análisis de las imágenes prehistóricas dentro del contexto concreto donde han sido realizadas, como en el caso del Solapo del Águila (Villaseca, Segovia) (Lucas, 1990). Destaca así su reconocimiento de un espacio sagrado en el que pinturas y grabados actúan como elementos que humanizan del territorio acercándose a la Arqueología Post-Procesual, dentro de la que ella misma se reconoce como estructuralista (Lucas, 1995:145).

También en el conocimiento del arte rupestre se ha volcado María del Carmen Sevillano San José, principalmente en la zona cacereña de Las Hurdes aunque también de Salamanca desde 1974. Su vinculación con la Universidad de Salamanca hizo que colaborase además de forma puntual con Socorro López Plaza en relación con la estatua de Tremendal de Tormes (Sevillano et al., 1996). El enfoque de sus investigaciones se ha centrado básicamente en

1 Además de diversos artículos en Zephyrus publicados entre los años sesenta y noventa y de su tesis doctoral, puede consultarse Sevillano 1991. definir tipológica, cronológica y culturalmente las piezas estudiadas, dentro de la línea positivista. Junto a las dos anteriores habría que añadir a $\mathrm{M}^{\mathrm{a}}$ Cleofé Rivero de la Higuera, estudiante de doctorado en la USAL en los años setenta, que se ocupa también del arte esquemático dentro de la zona extremeña ${ }^{2}$.

La última figura relevante es la ya mencionada $\mathrm{M}^{\mathrm{a}}$ Dolores Fernández Posse, con una trayectoria que se inicia en la Universidad de Granada en la órbita de Antonio Arribas pero cuya labor se desarrolla desde 1975 sobre todo en los servicios arqueológicos del Ministerio de Cultura. Sus trabajos en la cueva de Arevalillo (Segovia) la llevan a dedicarse a la caracterización de las cerámicas distintivas de Cogotas I y su evolución (Fernández-Posse, 1979, 1981, 1986), como venían haciendo sus colegas Molina, Arteaga, Jimeno y Delibes. Sin embargo, hay que señalar cómo incluye además una preocupación por las diferencias territoriales que se marcan en las manifestaciones materiales a lo largo del desarrollo de la Edad del Bronce. Primero lo hace apuntándolo con prudencia y reconociendo el limitado conocimiento que se tenía de los yacimientos, pero enseguida aprecia la importancia de las variaciones en lo que se conocía como la fase formativa de Cogotas I y también a partir del 1000 a.C. con la llegada de influencias exteriores que afectan de distintas maneras según las zonas (Fernández-Posse, 1982, 1986-87).

Tiempo después, su libro La investigación protohistórica en la Meseta y Galicia (Fernández-Posse, 1998) refleja un importante cambio en su orientación teórica, que venía produciéndose con anterioridad y se había manifestado en sus trabajos sobre Las Médulas (León) pero que no había alcanzado aún al ámbito prehistórico que analizamos aquí. Antonio Gilman (2007) ha destacado el valor de este paso hacia el funcionalismo, con una enorme atención a la crítica de los postulados normativistas anteriores que incluye sus propias tesis previas. En sus últimos años de trabajo empezó a dar cabida a una visión propia de la arqueología del género, si

2 Se encuentran artículos suyos en los números 23-24 y 30-31 de Zephyrus, sobre la cueva de Boquique y diversas estaciones de pintura rupestre. 
bien sólo llegó a desarrollarla para sus estudios relativos a la cultura castreña berciana (Fernández-Posse, 2000).

Otras prehistoriadoras han incidido en temas propios de la Meseta, aunque lo hicieran desde perspectivas más globales. Es el caso, por ejemplo, de Marisa Ruiz-Gálvez, que con sus incursiones en lo que se conoce como Bronce Atlántico ha incidido de lleno en la Meseta Norte ( $v d$. Ruiz-Gálvez, 1987, 1998; Fábregas y Ruiz-Gálvez, 1997). Tras destacar la presencia de un comercio común a todas las culturas del área, ha ido dotando a esos intercambios de un sentido social y también identitario, en el que lo simbólico e ideológico ha ganado mucho peso frente a lo puramente económico ( $v d$. Fernández-Posse, 1999).

La representatividad de estas investigadoras es difícil de evaluar. Si consideramos los estudios relativos a intervenciones realizadas en yacimientos calcolíticos y, sobre todo de la Edad del Bronce en los años ochenta en lo que hace referencia a los estudios cerámicos, se puede comprobar que las citas de trabajos anteriores se centran en el sector masculino de los investigadores $^{3}$. Ello no sólo se debería al peso del principio de autoridad y a que fuesen hombres los autores de todas las referencias de décadas anteriores, entre los que destacan Cabré y Maluquer junto a otros como Barandiarán, Almagro Basch o Alberto del Castillo; sino que también entre los estudios más recientes se da mayor relevancia a los realizados por varones. Así se pueden destacar las citas de Fernando Molina sobre los yacimientos de la Cuesta del Negro y Los Castillejos (Granada), de Juan $\mathrm{M}^{\mathrm{a}}$ Apellániz sobre el grupo de los husos (Álava), de Zamora Canellada sobre La Vaquera (Segovia), de Almagro Gorbea y Fernández Galiano sobre Ecce Homo (Madrid), de González-Tablas sobre la gravera de Puente Viejo (Ávila), de Alfredo Jimeno sobre Los Tolmos de Caracena (Soria) y los de Delibes sobre La Requejada y La Plaza (Valladolid). Junto a ellas, pero sin llegar a alcanzar tantas menciones, e incluso ignorándose en algunos artículos, están los varios trabajos de Fernández-

3 Hemos realizado un muestreo utilizando como base: Jimeno 1984, Jimeno et al.1988, Delibes et al.1990 y los artículos relativos a los yacimientos de Alar del Rey (Palencia),
Posse sobre la cueva de Arevalillo (Segovia) y sobre las cerámicas de Cogotas, los de López Plaza sobre las cerámicas eneolíticas, los de Blasco Bosqued sobre El Negralejo (Madrid) o los de Naranjo González sobre el Castillo de Cardeñosa (Ávila).

Sin entrar en mayores consideraciones, tan sólo querríamos mencionar el hecho de que los trabajos de estas investigadoras sobre cerámica se circunscriben a unas pocas publicaciones y un periodo de tiempo muy concreto de apenas un lustro (salvo en el caso de la madrileña Concha Blasco). Tal vez eso podría justificar desde el punto de vista académico su desaparición en las citas bibliográficas a favor de sus colegas masculinos, que sí publican trabajos sobre ese tema con mayor continuidad.

La lucha por la autoridad científica es un punto importante en el camino de asegurarse una posición dominante en la jerarquía de los valores científicos. La visibilidad de los trabajos propios, la posibilidad de hacerse un nombre conocido y reconocido, es un camino que abre la puerta a créditos, equipamientos técnicos, mano de obra y los servicios de una amplia burocracia científica (Bourdieu, 2012: 81-118). Pero el logro del prestigio depende a su vez de las instituciones donde uno haya estudiado, de su origen social y de los logros conseguidos anteriormente, que fundamentan las aspiraciones razonables. Todo ello dibuja el perfil de la situación de un campo científico en un momento determinado.

Siguiendo la línea marcada por Pierre Bourdieu (2009) se puede apreciar la relevancia de que los investigadores más exitosos estén bien situados dentro de los mecanismos de poder cultural. Aparte de la pertenencia a comisiones encargadas de financiar investigaciones y de nombrar a los nuevos investigadores o a institutos y centros de investigación, una de sus manifestaciones más visibles sería la pertenencia a los consejos de redacción y asesores de las principales publicaciones científicas, para lo cual nos hemos remitido a las reseñadas por Román y Alcain (2005).

Cogeces y Geria (Valladolid) y El Cogote (Ávila) en la revista Numantia, 4, Junta de Castilla y León, 1993. 
Revisando la presencia de los prehistoriadores que hemos ido mencionando, más allá de su inclusión en las revistas editadas por la institución a la que están adscritos profesionalmente, sólo Germán Delibes puede contarse en los consejos asesores de Trabajos de Prehistoria (entre 1997 y 2010), Zephyrus (desde 2005), Saguntum (desde 2003) y Spal. Ninguna otra de las figuras merece tales reconocimientos, por más que fuera del ámbito de Castilla y León sí tengan mayor consideración y relevancia mujeres dedicadas al periodo de la Prehistoria que nos interesa, como Concepción Blasco Bosqued, $\mathrm{M}^{\mathrm{a}}$ Isabel Martínez Navarrete y Marisa Ruiz-Gálvez.

\section{3. LA EXTERIORIZACIÓN DEL GÉNERO DESDE LOS AÑOS NOVENTA}

A partir de finales de los años noventa se aprecia la irrupción de un nuevo grupo generacional que va acompañado de un nuevo contexto que afecta a los enfoques teóricos de la investigación, así como de una mayor importancia de las líneas de pensamiento llevadas a cabo en el ámbito angloamericano. No se trata sólo de la atención a los trabajos que se realizan en otros países, sino sobre todo de que los jóvenes licenciados se ven en la tesitura de realizar estancias en centros extranjeros para completar su recorrido formativo con vistas a lograr una plaza en las plantillas docentes universitarias. Sin embargo, pese a la mejora en la aptitud de estos profesionales, la realidad de la universidad es que existe un exceso de profesores que ha creado un cuello de botella que no permite la consolidación laboral de la mayoría de becarios licenciados y doctores.

$\mathrm{Y}$ de nuevo el sector femenino resulta minoritario frente a los varones. No merece la pena hacer aquí un listado de investigadores, pero sí podemos apuntar que el dominio de los hombres continúa siendo apabullante (por más que la presencia femenina sea mayoritaria entre los estudiantes y aun entre el personal investigador en formación). Esto no se reduce sólo a la universi- dad, pues entre las empresas de arqueología, que llevan ya más de veinte años actuando en Castilla y León, las mujeres son excepcionales ${ }^{4}$.

Es ahora cuando la arqueología del género, que había tenido en los ochenta las primeras manifestaciones en España de la mano de Encarnación Sanahuja y otras investigadoras catalanas, empieza a ser motor de grupos de investigación, cursos y publicaciones (Sánchez Liranzo 2008). En el ámbito de Castilla y León se mantiene el interés de las mujeres por el estudio de las representaciones rupestres, entre las que destaca Blanca Samaniego, de la Universidad Complutense, dedicada en especial al territorio soriano. Sus trabajos están centrados en la lectura de los símbolos generando posibles interpretaciones a partir del espacio al que se encuentran ligados y, si fuera posible, a la temporalidad de la experiencia de su evocación; y lo hace siguiendo los principios de la semiología (Samaniego, 1999, 2003; Samaniego et al., 2002).

Junto a ella habría que sumar a Marta DíazGuardamino Uribe, cuya formación se gestó en la misma universidad madrileña. Sus investigaciones partieron en el ámbito del megalitismo salmantino (Díaz Guadarmino, 1997), si bien su tesis ha supuesto una ampliación del campo de atención y ha pasado a abarcar las estelas y estatuas-menhir desde el Neolítico a la Edad del Bronce, lo que incluye al menos parcialmente a la Meseta Norte. Adopta una perspectiva en la que la iconografía supone un importante punto de partida, pero centrada en la contextualización de estos hitos y su relación con el espacio prehistórico, su organización y la identidad de las gentes que lo ocuparon (Díaz-Guadarmino, 2004, 2006, 2008, 2011, 2012).

Por otro lado la especialización de Elisa Guerra Doce, de la Universidad de Valladolid, ha venido de la mano de dedicarse a indagar en el consumo de drogas y bebidas alcohólicas en los tiempos prehistóricos, en un contexto que en la mayoría de sus trabajos transciende lo local y alcanza una dimensión europea (Guerra, 2002,

4 Tal vez sí sea bueno mencionar a algunas de ellas, por más que sus incursiones en la investigación sean esporádicas, como María José Negredo García (ARATIKOS), Ana Viñé 
2005, 2006a, 2006b, Delibes et al., 2009). Pero no se ha limitado a documentar evidencias de su uso, sino que también ha reflejado su relación con determinados elementos simbólicos del arte (Guerra y Delibes, 2004, Fairén y Guerra, 2005). Más recientemente ha pasado a contemplar aspectos de diferenciación social centrados en el comercio a larga distancia y la desigual contextualización de elementos de cultura material en sepulcros megalíticos (Guerra et al., 2009), a tono con la arqueología postprocesual que en los años ochenta y noventa efectuaban autores como Kristiansen, Tilley o Earle, y ha desarrollado un proyecto de investigación en las salinas prehistóricas de Villafáfila (Zamora) (Abarquero y Guerra, 2010).

De manera tangencial a sus investigaciones sobre el Paleolítico, Ana Neira Campos (Universidad de León) ha abordado en varias ocasiones temas relativos al periodo que analizamos. No obstante, se ha reducido a una aproximación al mundo de la minería prehistórica centrada en la búsqueda de evidencias sobre dónde, cuándo y con qué medios, dentro de la órbita normativista y siguiendo en buena medida la estela de Blas Cortina (Matías et al., 2003, Fernández Manzano y Neira, 2006-07, Neira et al., 2007). Con ésta ha colaborado puntualmente Lucía Pérez Ortiz, de la misma universidad, cuyos pocos trabajos han estado centrados en el análisis de la cultura material y el territorio en el Bronce Final y el Primer Hierro (Blanco y Pérez, 2005, Pérez, 2005, Fuertes y Pérez, 2008).

Finalmente, Alejandra Sánchez Polo es una de las jóvenes investigadoras que ha surgido en los últimos años de la Universidad de Salamanca y se sitúa en el post-procesualismo. Sus trabajos abordan una revisión de las interpretaciones funcionalistas relativas a las estructuras de los poblados prehistóricos para atender más a los aspectos simbólicos (Sánchez, 2010, 2012a, 2012b). También ha planteado superar las cuestiones meramente clasificatorias o cronológicas de las decoraciones cerámicas y centrarse en lecturas sociales o territoriales (Sánchez, 2011).

\section{GÉNERo}

En todo este periplo se advierte, sin embargo, que pocos han prestado atención a la presencia de mujeres. Siguiendo los esquemas normativis- tas se ha generalizado el uso de la figura del hombre como actor principal de las actividades desarrolladas por las gentes prehistóricas: pastores, agricultores, jefes, metalurgos, etcétera.

El campo de las representaciones artísticas es uno de los pocos donde la presencia de mujeres no puede quedar oculta (fig. 2) y sus imágenes han permitido abordar diversas interpretaciones desde hace ya varias décadas. Las primeras inmersiones en este ámbito se produjeron en los años cincuenta de la mano de Teógenes Ortego, cuyos significativos estudios encontraron continuidad en la persona de Juan Antonio Gómez Barrera desde 1980. Teógenes Ortego (1951) reconoció dentro del monte soriano de Valonsadero, en el Peñón de la Visera (Soria), una figura femenina con un extraño artefacto enmangado en forma de azada, que identificó con los bastones de cavar visibles en la pintura levantina. Así mismo este autor destacó la composición de Los Peñascales II, en la que catorce figuras femeninas rodean a otra de mayor tamaño y con los senos marcados, donde apreciaba relación con ceremonias rituales propias del ciclo matriarcal agrícola, que practicarían sólo las muchachas núbiles (idem: 299). En el Covacho del Morro una parte de sus pinturas se ha relacionado con la domesticación, en concreto una sucesión varón-cuadrúpedo-mujer-macho cabrío que aparece dentro de un amplio panel cuya lectura está ligada a la vida, la muerte y la fertilidad (Gómez Barrera, 2001: 107-134).

Entre los grabados rupestres sobresalen algunos de la Cueva de la Santa Cruz (Conquezuela, Soria). Siguiendo lecturas de Ortego, Juan Antonio Gómez Barrera expone la presencia de una representación femenina "divinizadora" en el Panel B y, en el Panel D, de un grupo de 23 antropomorfos (11 varones y 11 mujeres en torno a un varón de mayor tamaño) que parece realizar una danza. A un lado las figuras se disponen entrelazadas y con los brazos en horizontal o caídos, mientras al otro lo hacen sueltas y con los brazos levantados (Ortego, 1956, Gómez Barrera, 1992: 93-101).

Dentro del territorio segoviano el trabajo de Rosario Lucas Pellicer ha establecido otra referencia significativa en la escena 20 del Solapo del Águila (Villaseca, Segovia), donde se ha identificado una pareja que une sus manos (el hombre sujeta un instrumento de largo mango) 


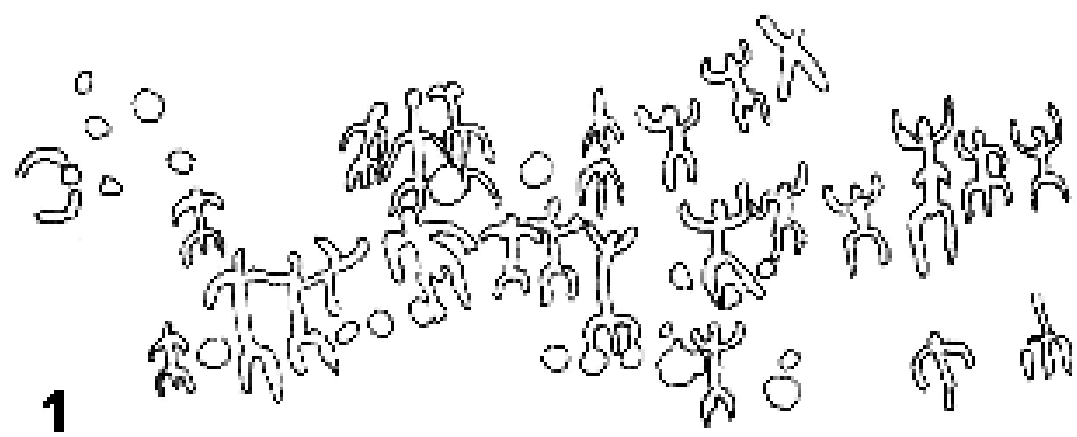

2

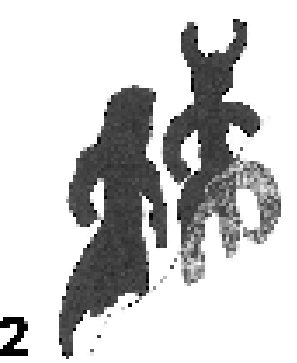

3
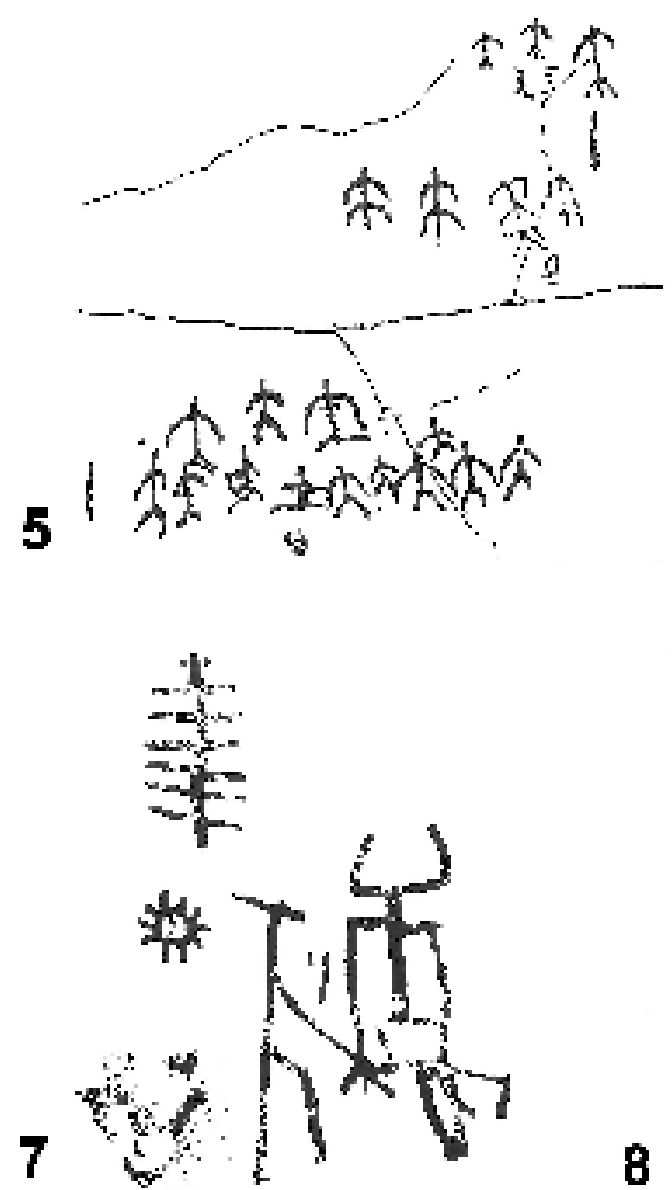

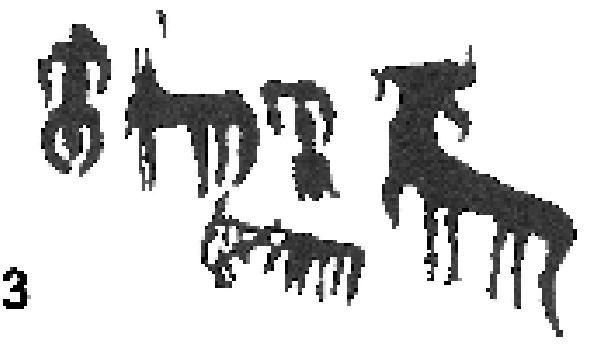

4
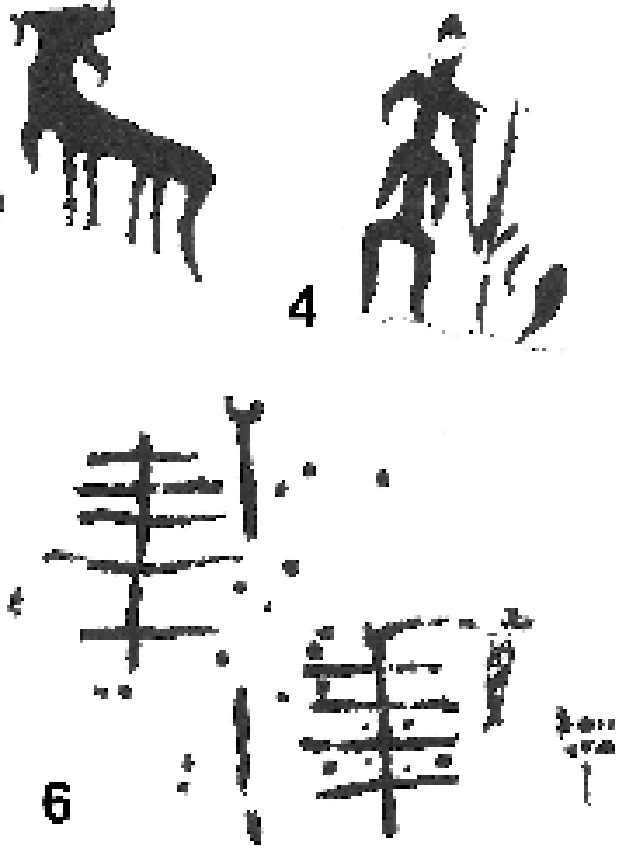

the

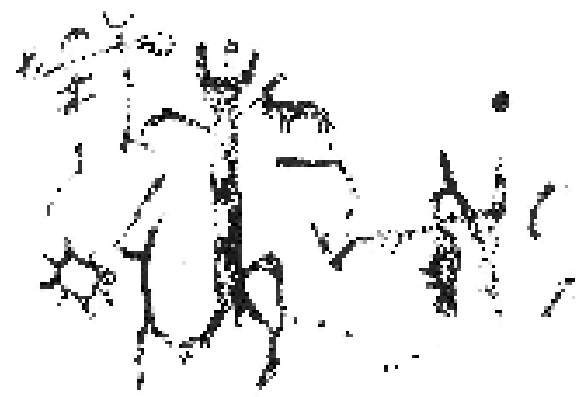

Figura 2. Representaciones de arte rupestre: 1. Cueva de la Santa Cruz, panel D; 2. Barranco de Valdecaballos, Valonsadero; 3. Covacho del Morro, Valonsadero, 4. Peñón de la Visera, Valonsadero 5. Los Peñascales II, Valonsadero (Soria); 6. Solapo del Águila, Grupo 8, 7. Solapo del Águila, Grupo 20 y 8. Solapo del Águila, Grupo 27 (Segovia). 
junto a dos ramiformes separados por un punto. La lectura del conjunto se relaciona con ceremonias matrimoniales, lo que se reforzaría por la relación entre el falo del hombre y el objeto enmangado que sujeta, así como por la asociación vegetal-sol (Lucas, 1990: 203-5). La escena 27 también resulta relevante, con un grupo de mujeres danzando en la parte alta y, debajo, un conjunto con un individuo itifálico de apariencia animal que parece presto a realizar un sacrificio; todo ello inmerso en lo que parece una procesión (idem: 205). La explicación de todo ello está basada, según Lucas Pellicer, en el principio binario hombre-mujer, sol-vegetación, cielo-tierra, con unas referencias que se repiten en el conjunto del Solapo en relación a su unión fecundante. En este punto cabría plantearse la transcendencia del hecho de que el personaje principal de la escena 27 , quien parece ser el centro de todo el grupo y ejecutante del sacrificio, sea un hombre.

Parece apreciarse en muchas de las representaciones una mayor relevancia de las figuras masculinas, por más que la identificación del sexo sea difícil por su esquematismo. Entre los adornos y elementos peculiares que podrían conferir una atribución especial a determinadas imágenes, se incluyen unos remates de cuernos que se dibujan en la cabeza de antropomorfos que portan lo que se interpreta como armas, en concreto arco y lanza (Lucas, 1992: 269-70). Ese mismo tocado se encuentra en figuras claramente masculinas que podrían configurarse como algún tipo de hechiceros u oficiantes de rituales, como en las mencionadas escenas 20 y 27 del Solapo del Águila; pero también en la escena 8 del mismo enclave, que se asemeja a otra del abrigo del Prado de Santa María (Pedrajas, Soria) con motivos que simbolizan la ascensión de mediadores humanos hacia la morada de la divinidad (idem: 272). Con todo, estas interpretaciones que destacan la aparente presencia de los individuos masculinos como miembros activos de la sociedad, frente a una mayor pasividad o un papel secundario de las mujeres, ha sido denunciada por diversas autoras (Díaz-Andreu, 1998b: 40-2, Escoriza, 2002) como un lastre en la investigación del arte rupestre desde el momento en que se da preferencia a la identificación de las figuras representadas como varones. Así es como en el arte levantino se identifican como hombres a las figuras que aparecen en escenas de caza, lucha o con motivos de tipo religioso o ritual y como mujeres las de escenas de danzas o las de actividades aparentemente productivas, pero que se valoran con un significado mágico (idem: 43-4).

Sobre las creencias, los estudios generales establecen que en los primeros milenios de economía productiva, el menos entre el Neolítico y el Bronce Antiguo, el papel fundamental en el panteón de divinidades lo ocupa una DiosaMadre de la fertilidad que rige la fuerza reproductora de la tierra. Sería con la Edad del Bronce cuando cambia el panorama religioso, al amparo del establecimiento de jefaturas y de actividades artesanas como la cerámica o los metales, que no dependen directamente del ciclo anual (Eliade, 1974: 79-83).

De hecho Marija Gimbutas ya puso en evidencia la importancia de las diversas diosas reconocidas entre los primeros agricultores del Neolítico, en un cuadro mitológico donde no existiría polarización entre elementos masculinos y femeninos y ambos se adscribirían integrados al ciclo de la vida de la naturaleza. Sería con el inicio de la Edad de los Metales cuando se impondría el patriarcado, un mundo con diferentes simbolismos y valores (Gimbutas, 1991: 2735). El concepto de Diosa-Madre ha sido, sin embargo, criticado y debe ser valorado con detenimiento (Conkey y Tringham, 1995). Los indicios de que algo está ocurriendo en el imaginario prehistórico en esta época resultan estimulantes, si bien es indudable que las sociedades prehistóricas tienen una concepción del tiempo y el espacio distinta a la actual y que para desentrañarla convendría conocer sus relatos mitológicos (Hernando, 2002).

Sería interesante indagar en cómo evolucionan las creencias en la Meseta Norte. En los enterramientos colectivos del Neolítico Final se han recogido unas espátulas de hueso con representaciones de mujeres en su mango (fig. 3). El caso más evidente es el del sepulcro palentino de La Velilla (Osorno, Palencia), pero se conocen otros más esquemáticos en el del Miradero (Villanueva de los Caballeros, Valladolid) (Delibes y Zapatero, 1995 y Delibes et al., 1987, respectivamente). Estos objetos se presentan sólo en los sepulcros megalíticos y otros enterramientos colectivos sincrónicos, pero desaparecen con la aparición de los primeros objetos de 


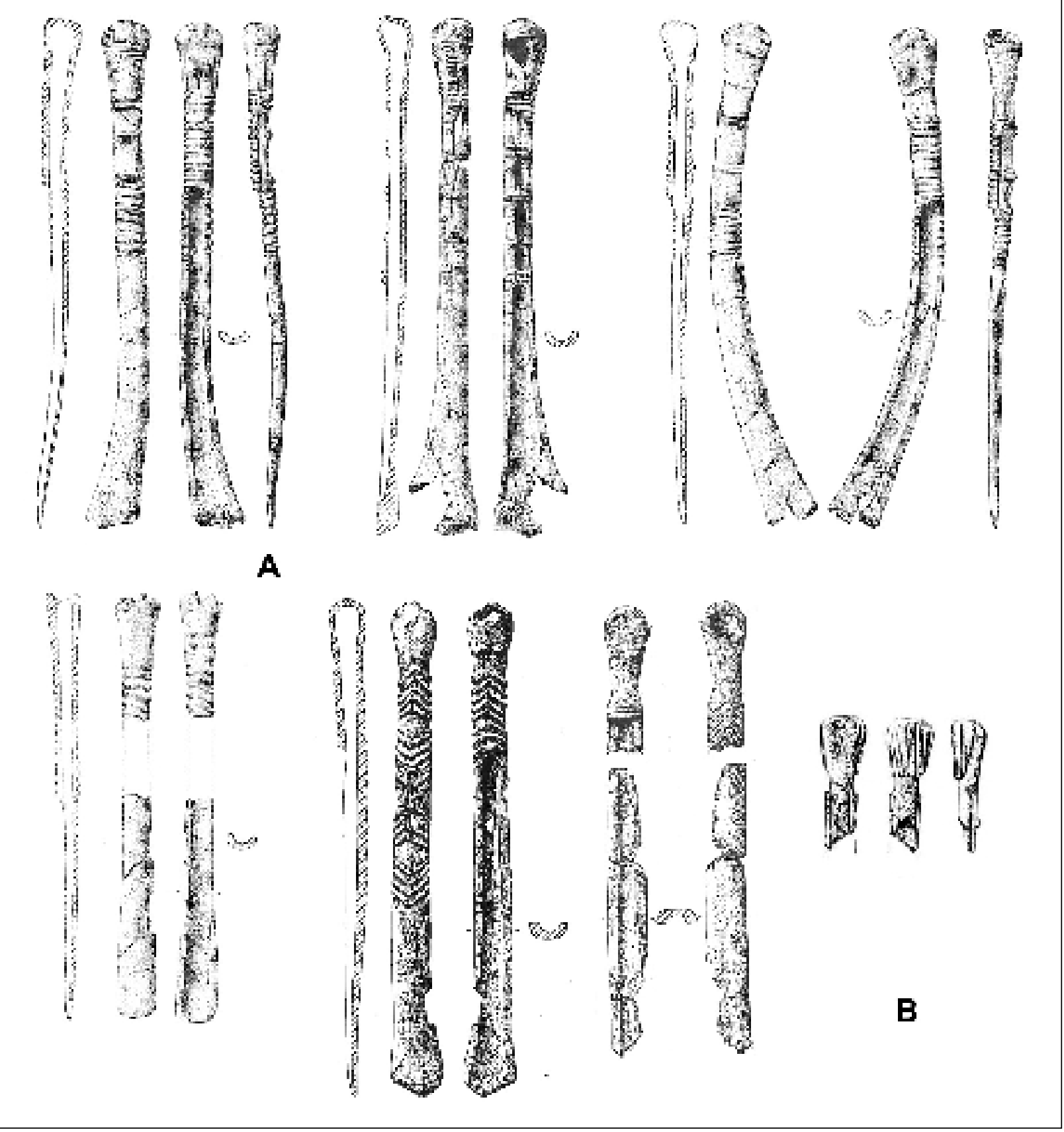

Figura 3. Ídolos-espátula de A. El Miradero (Villanueva de los Caballeros, Valladolid) y B. La Velilla (Osorno, Palencia). Según Delibes y Zapatero.

cobre, lo que estaría indicando posiblemente un cambio en el imaginario religioso de las gentes prehistóricas. Uno de los individuos enterrados en El Miradero concentraba la posesión de uno o varios grandes collares y once espátulas (que en el resto de los individuos no pasaban de dos), lo que deja traslucir que hubo de tener una especial estimación en su grupo. Curiosamente se trata de un varón adulto, por más que aglutine los adornos y las representaciones femeninas de los ídolos-espátulas (Guerra Doce et al., 2009: 53-4).
Dejando al margen estas incursiones en las representaciones prehistóricas, uno de los primeros trabajos que llamó la atención sobre el papel de las mujeres en lo que afecta al ámbito de nuestro texto fue Marisa Ruiz-Gálvez (1992: 220-2) al referirse a los sistemas de matrimonio y transmisión de la herencia. Partiendo de escritos de Jack Goody y Ester Boserup, resaltaba la relación entre la agricultura itinerante, de azada, y el mantenimiento de la exogamia y la compra de la novia. La razón según estos antropólogos 
reside en que el trabajo del campo era realizado básicamente por la mujer y los hijos, de lo que derivaría que el esposo deba compensar a la familia de la novia por la pérdida de una productora y, sobre todo, de los descendientes que engendre. Se valoraría especialmente a la mujer como trabajadora de la tierra, frente a los grupos estantes y donde las parcelas son más extensas, en los que la endogamia es más frecuente. Una agricultura con campos que se agotan y obliga a la movilidad de los poblados se habría mantenido en casi todo el territorio peninsular, exceptuando el Sureste, hasta la transición a la Edad del Hierro. A partir del siglo X a.C. se conocen en el Occidente de la península testimonios de joyería áurea, generalmente torques, cuyo empleo se relaciona con jóvenes mujeres en edad de contraer matrimonio, y más específicamente se interpretan como objetos usados en las transacciones matrimoniales. Estas sociedades manifestarían a través de estos torques el establecimiento de alianzas entre grupos exógamos y, según indica Ruiz-Gálvez, la existencia de una política de intercambios y alianzas (en el marco de unas relaciones comerciales de creciente importancia que movilizarían recursos agropecuarios y mineros) que había de servir para adquirir los objetos de prestigio luego utilizados en transacciones sociales como la compra de novia (idem: 236).

Las repercusiones de estas ideas no se hicieron esperar demasiado y se pueden apreciar en el estudio del fragmento de un torques tipo Tara encontrado en Castrojeriz (Burgos), donde se llega a plantear la posibilidad de que las joyas de oro hubieran llegado como parte de las pertenencias de mujeres foráneas, tal vez de la costa atlántica francesa (Delibes et al., 1995). Curiosamente Delibes desvirtúa aquí la tesis defendida por Ruiz-Gálvez de que las piezas de oro sirviesen para comprar a las mujeres, dentro de un sistema donde hubiera que compensar por su valor productivo, para sostener su condición de dotes que -en la tesis de Marisa RuizGálvez- sólo están presentes con posterioridad cuando los poblados son estables y se valora la propiedad de la tierra, que trabajan principalmente los varones. La hipótesis de la llegada de mujeres desde territorios muy distantes en el marco del establecimiento de alianzas habría de llegar al paroxismo cuando años después se aplicó para justificar la amplia dispersión de las cerámicas Cogotas I por buena parte de la Península Ibérica, como veremos en el siguiente apartado.

Ruiz-Gálvez (1992: 222), en el trabajo que ya hemos mencionado, recoge referencias a objetos que viajan largas distancias referidos a un periodo que se inicia en el Neolítico Final y continúa hasta la Edad del Bronce abarcando toda la Europa Atlántica (Inglaterra, Francia y Península Ibérica). Sobre el contexto de hallazgo, en los primeros tiempos y hasta el Bronce Antiguo, suele producirse en el interior de las tumbas y se interpreta como manifestación del intercambio de bienes de prestigio entre los jefes principales; mientras que a partir de ese momento se concentran más bien en depósitos y ocultamientos de metales, situados en general cerca de áreas mineras (idem: 226-7).

Durante los noventa se ha reflejado en los estudios un creciente interés por estudiar los circuitos de intercambio, sobre todo a partir del desarrollo de la teoría de los Sistemas Mundiales y su organización centro-periferia-margen para el mundo mediterráneo del Bronce Final por parte de Sherratt (1993). Ello ha incidido en un mayor interés por la búsqueda de las redes de intercambio regionales de las que pudiera haber quedado testimonio a través de metales, cerámicas, textiles, ganado o sal. En ese contexto la búsqueda de esas vías estables, que fuesen conducto continuado de intercambios de excedentes entre las élites de dos zonas distantes ( $v d$. Mederos, 1995, Ruiz-Gálvez, 1995), ha relegado el estudio del papel que las relaciones matrimoniales adquieren en muchos pueblos. $\mathrm{Y}$ es que incluso en grupos donde lo normal es la endogamia, no faltan casos donde se contemplan excepcionalmente uniones con mujeres procedentes de tribus extranjeras y lejanas. La finalidad de estos matrimonios era establecer o consolidar intercambios comerciales pacíficos, como puede apreciarse por ejemplo entre los Baruya (Godelier, 2005: 36). En este caso se entregaban una serie de bienes, barras de sal y cauris en cantidad desorbitada, con la intención de romper los derechos de su linaje original sobre la mujer que 
había de desplazarse a un distante pueblo extranjero $^{5}$. No era el intercambio de objetos lo que garantizaba la fiabilidad y la continuidad, sino el de personas; por más que para el ámbito prehistórico el movimiento de los objetos haya ocupado el principal punto de atención en detrimento de las relaciones humanas.

El mundo funerario, uno de registros donde con mayor facilidad se encuentra la posibilidad de referirse a las peculiaridades marcadas por el género y la identidad (vd. Prados 2012), no ha escapado a esta realidad. El trabajo de síntesis realizado hace más de veinte años por Ángel Esparza (1990) obvia estas cuestiones. Al considerar en su conjunto las prácticas funerarias de la Edad del Bronce, examina el número de enterrados y su posición, sus ajuares, las peculiaridades del contenedor, los espacios funerarios y la heterogeneidad de manifestaciones. Sin embargo alude sólo sucintamente a la condición masculina o femenina de los restos inhumados para reconocer una diferenciación en su colocación, que sería decúbito lateral derecho para los hombres (coincidente con lo testimoniado por las más antiguas tumbas dotadas de ajuar campaniforme) e izquierdo para las mujeres; si bien la no coincidencia completa de esta propuesta con la realidad de las determinaciones sexuales le lleva a proponer una revisión de los análisis antropométricos (idem: 127).

Los estudios más recientes, como el de Francisco Fabián sobre el valle Amblés en época calcolítica (Ávila), toman muy en cuenta la condición sexual de los difuntos gracias a los análisis antropométricos, por más que no alcancen a consideraciones relativas a las actividades de mantenimiento que permiten visibilizar lo relativo a las experiencias de las mujeres ( $v d$. Montón 2012). Así este autor destaca el predominio de restos masculinos en su muestra de estudio, por más que ambos sexos compartan los mismos espacios funerarios, y señala algunos elementos de diferenciación: la menor estatura de las mujeres, el caso de una con artrosis en las dos piernas -lo que achaca a cargar frecuentemente con

5 En otros tipos de matrimonio baruya, los intercambios que se realizan entre familias no buscan una compensación que acabe con la deuda creada por la marcha de la mujer, sino pesos a la espalda- y se plantea la posibilidad de que la dieta de las mujeres fuera más rica en vegetales y productos lácteos que la de los hombres, entre los que pesaría más la ingesta de carne (Fabián 2006: 436-40). Por contrario en un trabajo posterior sobre el enterramiento colectivo (con seis inhumados) del Cerro de la Cabeza (Ávila), no se aprovecha para valorar suficientemente la peculiar aparición de puntas de flecha en el interior del cuerpo de cuatro de los muertos, uno de los cuales era la única mujer presente en el conjunto (sobre la violencia contra las mujeres $v d$. Escoriza, 2006: 23-24).

El estudio se centra en explicar cómo estas tumbas podrían corresponder a un ritual excepcional que se saldría de la norma común (Fabián y Blanco, 2012: 112-4), pero no incide apenas en aspectos como que la mujer es la única que se libra de padecer artrosis. $\mathrm{Al}$ respecto se alude a su edad, estimada en 18-20 años, para justificarlo pero en el mismo yacimiento hay dos varones de 15-16 años que sí presentan esta patología (idem: 102-110). Tampoco se llega a considerar si había tenido ya algún embarazo y parto o no, ni se trata de encontrar evidencias de lesiones o huellas derivadas de trabajos distintos a los de sus coetáneos varones, sobre los que se alude repetidamente a hernias por llevar pesos con la cabeza o la espalda, a un intenso deambular por terrenos accidentados e incluso evidencias de que uno pudiera haber desarrollado trabajos de leñador habitualmente. La incidencia de la artrosis o de distintos tipos de traumatismos cabe ser valorada como distinta según las actividades que han desarrollado hombres y mujeres; de este modo una de las posibles patologías femeninas sería artrosis en las manos, como ocurre con una mujer del Cerro de la Encina (Monachil, Granada), y sobrecarga muscular en las extremidades superiores (Sánchez Romero, 2008: 17 y 2009: 77). Tampoco se ha considerado la posible existencia de actividades de mantenimiento y cuidado de determinados individuos infantiles, enfermos o incapacitados para cuidar de sí mismos por razones de edad ( $v d$. Alarcón 2007).

que los intercambios de regalos y servicios entre cuñados no desaparecen y se mantienen continuamente (Godelier 2005: 37-40). 
La condición femenina de tres cráneos aparecidos en un hoyo del yacimiento calcolítico de Los Cercados (Mucientes, Valladolid) sí da pie a García Barrios (2007) para reflexionar sobre las circunstancias violentas de su muerte, por un golpe en la cabeza en cada una de ellas, y la peculiaridad del relleno que colmataba la fosa en cuya base se depositaron. La interpretación establecida por García Barrios se dirige a justificar el acto como un ritual que asegurase la prosperidad de la comunidad que lo realiza, dando satisfacción a una divinidad fecundadora (idem: 52-3).

En lo que respecta a la Edad del Bronce, el trabajo inicial de Ángel Esparza se ha visto enriquecido en el último lustro con un intenso proyecto de investigación dirigido por él mismo. Entre sus propuestas se ratifica la diferente postura de inhumación según el sexo del difunto, aunque de nuevo se menciona la falta de significación estadística de la muestra (Esparza et al., 2012a: 282). El mayor avance, sin embargo, se produce de la mano de los análisis antropológicos, que permiten apreciar el peso de los problemas derivados de los partos o los embarazos en la elevada mortandad femenina entre los $20 \mathrm{y}$ 35-40 años (idem: 296). Fijar la edad de inicio de los partos en los 20 años podría resultar algo elevada, pero de cualquier forma tiene unas importantes implicaciones a la hora de definir comportamientos sociales. Así mismo cabría valorar la ausencia de restos perinatales y neonatos junto a las mujeres. En varias ocasiones se ha aludido a la posibilidad de que estos enterramientos, que afectan a un sector reducido de las poblaciones prehistóricas, interesen sólo a individuos muertos en especiales condiciones e incluso ajusticiados (Bellido, 2004, Esparza et al., 2012b). No sabemos si en estas sociedades prehistóricas se llegaba a castigar el adulterio, pero es otra posible explicación a estos enterramientos anómalos.

Sobre las condiciones de vida, se indica la mayor incidencia de las caries en las mujeres que en los hombres, lo que se interpreta con dudas como testimonio de un diferente patrón alimenticio, con mayor consumo de vegetales entre las primeras y de carne entre los segundos, si bien también se plantea que su origen sea debido a otros motivos (Esparza et al., 2012a: 301-2). De cualquier modo resulta sugerente pensar que las evidencias pudieran responder a que las mujeres dañaban sus dientes mascando trigo o cebada para ayudar en la fermentación de alguna bebida alcohólica, mientras que los hombres organizaban partidas de caza, reservándose para ellos mismos el consumo de buena parte de sus presas. En este sentido el análisis de contenido de distintos recipientes parece confirmar ese procedimiento de elaboración de la cerveza (Guerra, 2006b: 70-1), labor que seguramente sería propia de las mujeres, por más que su consumo se atribuya generalmente a los hombres (Sánchez Romero et al., 2007: 74).

Poco se ha concluido hasta ahora sobre el papel de los depósitos secundarios y las tumbas reutilizadas. Ni siquiera el estudio de los ajuares parece conducir a consideraciones generales, dada su escasa aparición en contextos funerarios (Esparza 1990: 128-9), frente a lo que ha deparado, por ejemplo, en el ámbito argárico (Montón 2010). Tampoco se ha incidido suficientemente hasta ahora en la importancia de las relaciones de parentesco. Los pocos enterramientos conocidos y su relativa dispersión, con pocos individuos por yacimiento, no facilita abordar estudios como los emprendidos en tierras argáricas que han permitido demostrar que los varones eran más heterogéneos que las mujeres, así como que no todos los varones adultos se enterraban en la comunidad donde vivían. A partir de ahí se ha supuesto que tenían una mayor movilidad tras el matrimonio, dentro de una posible sociedad matrilocal ( $v d$. Chapman, 2010: 166-7).

En los últimos años, sin embargo, se ha venido poniendo el acento en la cuestión de las actividades de mantenimiento que se relacionan con la gestión de la vida diaria, tales como cocinar, realizar vestidos, transportar agua y otros productos, criar a los niños, preparar y administrar medicinas y otros remedios, labores de limpieza y otras (González et al., 2007 y 2008). La escasez de contextos domésticos en los yacimientos meseteños, donde predominan los 'campos de hoyos' con sus estructuras subterráneas pero no aéreas, parece haber dificultado el desarrollo de estudios acerca de la relación entre los espacios de la vida diaria y la cultura material.

Lo relativo a la preparación de alimentos y a la elaboración de telas es uno de esos aspectos marginados hasta ahora ( $v d$. Sánchez y Aranda 2005). Este olvido lo ha venido a romper un reciente análisis del contenido de los hoyos en 
cuatro yacimientos del interior peninsular que ha constatado un comportamiento pautado durante el Bronce Medio que discrimina hoyos con molinos en buen estado (a veces con pesas de barro cocido) de otros que contienen piezas de hoz, en ocasiones junto a útiles metálicos y fragmentos pequeños de molinos, y de otros con recipientes cerámicos. Tal reiteración se atribuya una intención de agrupar simbólicamente actividades afines que, pese a manifestarse sólo de forma implícita, pudieran fundarse en razones de género (Sánchez Polo, 2012b: 85-7).

Pese a todo no faltan las investigaciones sobre el papel que la mujer juega en la cotidianidad y sus actividades, puesto que en estos años Javier Abarquero (2005: 446-7) ha destacado su importancia en las labores alfareras de las sociedades primitivas, asociando diversos ejemplos tomados de sociedades tradicionales a la posibilidad de que ocurriera lo mismo en la Edad del Bronce de la Meseta Norte. Su aportación, no obstante, se mantiene en un ámbito puramente especulativo ya que el mayor soporte a esta posibilidad procede, como él mismo refiere, de los comentarios realizados en una época tan distante como 1927 por Blas Taracena (1927: 10) en relación al pequeño tamaño de las ungulaciones marcadas en el poblado de la Edad del Hierro de Izana (Soria), a las que achaca ser "obra de mano femenil". Esto cobra singular importancia desde el momento en que buena parte de su tesis sobre la dispersión de las cerámicas Cogotas I se sustenta sobre la posibilidad de que sean las mujeres el motor de tal movimiento.

Javier Abarquero llega a sostener así la existencia de una exogamia de largo alcance que propiciase la salida de estas cerámicas del área nuclear de Cogotas. Según este planteamiento serían las mujeres quienes se establecerían en enclaves alejados de su lugar de origen y, una vez allí, continuarían elaborando las mismas vasijas de estilo Cogotas que hacían anteriormente, al tiempo que sus modelos serían copiados por las mujeres de la aldea donde se habían establecido por matrimonio (Abarquero, 2005: 444-52). Llama la atención cómo descarta que las mujeres foráneas, que supuestamente llegarían a la Meseta Norte dentro de ese recurso a los matrimonios exogámicos, lograsen influir en las cerámicas locales porque su falta de elementos decorativos distintivos y su heterogeneidad tení- an poco que aportar al gusto estético de las gentes del interior. Y al mismo tiempo sostiene que las cerámicas Cogotas I constituyen una vajilla de lujo que se incorpora como un tipo suplementario que complementa a las vajillas más simples de los pueblos periféricos (idem: 452-61), con lo cual parece dar preferencia a la explicación del movimiento de las cerámicas y los modelos estéticos frente al de mujeres. Este olvido de las mujeres como autoras de las vasijas cerámicas y su papel en la creación de las piezas decoradas con estilo Cogotas continúa en su último trabajo sobre este tema (Abarquero, 2012: 88-97).

El tema de la alfarería es recurrente en las referencias relativas a la separación de actividades según el sexo. Al respecto puede mencionarse también cómo al explicar el modo de vida de la población de Cueva Mayor, Teresa Mínguez señala que los hombres se ocuparían de salir a pastorear, mientras las mujeres se quedaban en la zona de vivienda cuidando a los niños, elaborando queso y la cerámica de uso diario. Sin embargo ella misma duda a continuación del papel exacto de hombres y mujeres en los trabajos alfareros y llega a citar a van Berg para admitir la posibilidad de descartar la participación femenina (Mínguez, 2005: 217-8). Sin duda para profundizar en todo lo anterior habría que contar con estudios como el que Laia Colomer aborda para la tecnología de elaboración de las vasijas en El Argar y que le lleva a proponer un modelo de producción femenino dentro del ámbito doméstico donde el aprendizaje se produce por convivencia directa de las hijas con las tareas cerámicas (Colomer, 2005: 207-8).

Otro caso significativo de ocultamiento del papel femenino en las actividades prehistóricas puede encontrarse en el estudio de las explotaciones salinas de Villafáfila. Las numerosas ilustraciones que acompañan al texto de una de sus publicaciones, reconstruyendo los procesos de formación del registro arqueológico, están protagonizadas en todo momento por varones, obviándose el papel de las mujeres (Abarquero et al., 2010). El olvido resulta más lamentable aún puesto que uno de los restos encontrados consiste en la tumba de una joven de 13-14 años, que es interpretada como perteneciente a "una familia aristocrática" y para la que se propone que pudo ser miembro de una élite hereditaria que controlase la producción de la sal (idem: 
112-4). Así mismo ello no impide que en otro lugar no se descarte por completo que esta muchacha hubiera trabajado en los secaderos de sal (Delibes y Val, 2007-08: 801). Este punto tiene una transcendencia aún no calibrada y que se relaciona con la posibilidad de que los jefes estuvieran o no libres de realizar trabajos, dedicándose en el primer caso sólo a administrar y gestionar los recursos, y también con la distinta participación en determinadas tareas según los sexos (Díaz-Andreu, 2005: 22-34). La identificación de las jefaturas y del alcance de su actividad se mantiene aún como una tarea pendiente más allá de la propuesta de que las élites controlasen el proceso de producción de la sal y que fuesen hereditarias (Delibes et al., 1998, Abarquero et al., 2010: 114-6).

El alcance de las generalizaciones resulta absurdo en casos como cuando se establece que los elementos simbólicos de estatus social elevado entre los grupos Cogotas I determinan que las armas corresponden a los hombres y los adornos a las mujeres (Celis et al., 2007: 171). Sin ir más lejos, cabe citar las tumbas con ajuares campaniformes donde conviven armas de cobre (puñales y puntas de jabalina) junto a diademas o fundas de botones de oro (Martín Valls y Delibes, 1989). Y del mismo modo se le puede enfrentar que las mujeres también han sido protagonistas de episodios bélicos, llegando a existir en algunas culturas un grupo significativo de enterramientos femeninos con armas; pero además pueden ser enterradas con puñales como ocurre en las tumbas del mundo argárico (Sanahuja, 2007). Incluso en ámbitos ajenos a la Meseta Norte se han descrito varios ejemplos de trabajo femenino en contextos poco tratados, como la talla lítica, el pulimento de la piedra o la metalurgia ( $v d$. Sánchez Romero, 2005). Se ve una vez más la necesidad de romper con ideas preconcebidas y dar paso a visiones interpretativas renovadas.

Creo que puede apreciarse que el género es un elemento aún poco valorado y que casi aparece como un elemento accesorio dentro del discurso principal de las investigaciones en la Meseta Norte. Se echan de menos numerosos temas, como por ejemplo el de las unidades domésticas, pero sin duda el avance de los enfoques interpretativos actuales irá cambiando este panorama.

\section{Conclusión}

Hoy no podemos dejar de considerar como muy relevante el adoptar una perspectiva de género en el estudio de la Prehistoria. Sin embargo, en apariencia sólo en los últimos años resulta posible detectar en este grupo de investigadoras una preocupación por tales cuestiones mayor que la existente entre sus colegas varones. Los temas que han venido tratando resultan parecidos, surgidos en general en la órbita del normativismo y actualizados con enfoques postprocesuales, y se refieren a las clasificaciones tipológicas, al poblamiento, a las costumbres funerarias y al mundo simbólico de las manifestaciones artísticas y rituales, sin mayores pretensiones de definir la presencia de la mujer. Y ello pese a la relevancia de los trabajos de autoras como $\mathrm{M}^{\mathrm{a}}$ Rosario Lucas Pellicer o $\mathrm{M}^{\mathrm{a}}$ Dolores Fernández-Posse.

Parece claro que se cumple uno de los aspectos a los que se enfrentan las reivindicaciones de la arqueología feminista, el dominio de los hombres en el ámbito académico de los departamentos de Prehistoria de las universidades de Salamanca, Valladolid, Burgos y León. En esta zona parece haber cierto retraso en la incorporación de mujeres a las plantillas universitarias en relación con el conjunto de España, donde en los noventa ya el $44 \%$ del profesorado fijo eran mujeres (Díaz-Andreu, 1998a: 139), pero además se manifestaba en esos años dentro de Castilla y León una importante continuidad en los equipos de investigación. Fernández-Posse (1998: 237) ponía entonces de relieve cómo se mantenían desde hacía dos décadas los mismos profesionales, con las mismas bases teóricas y planteamientos y los mismos principios e instrumentos prácticos.

Sin duda alguna el papel de las mujeres prehistóricas es diferente al de sus contemporáneos varones, pero la condición sexual de las investigadoras que hemos mencionado no resulta $a$ priori determinante en sus enfoques. En principio se alejan de las consideraciones de la arqueología feminista, en el sentido de reconfigurar la forma de hacer arqueología a partir de puntos de vista que pusieran de relieve la marginalidad de la mujer en los estudios científicos o en el de romper con el discurso patriarcal y el relato impersonal. 
Al mismo tiempo se detecta la marginalidad de las mujeres, relegadas a asuntos "menores" (Berrocal, 2009: 29) que dejan a un lado temas estrella. Mientras la teoría y la práctica arqueológicas se mantienen en manos de hombres, que se ocupan de establecer las líneas maestras tradicionales de la Prehistoria (clasificaciones tipológicas, definición de fases culturales y sociales, así como el estudio de los yacimientos más notables, suelen caer en su esfera de trabajo), las mujeres se centran en temas como manifestaciones artísticas y simbólicas y actividades rituales. Aún los trabajos iniciales de Fernández-Posse y López Plaza relativos al establecimiento de tipologías cerámicas, dentro del ámbito general de la estructura científica, quedaron rápidamente oscurecidos por las aportaciones de sus colegas masculinos. Las figuras que han destacado durante la última década en este campo incluyen para la Edad del Bronce a Germán Delibes, José Antonio Rodríguez Marcos y Javier Abarquero (p.e. Rodríguez, 2008; González Fernández, 2009), mientras que para el Calcolítico lo más reciente sería obra de Juan Francisco Fabián y Rafael Garrido Pena (Fabián, 2006; Garrido, 2000). Esta realidad coincide en buena medida con lo ocurrido, por ejemplo, en la investigación prehistórica andaluza hasta hace pocos años, donde las mujeres reproducían las líneas directrices marcadas por sus compañeros, sin incidir en el desarrollo teórico (Sánchez Liranzo, 2005: 470-2).

Una vez definido este panorama se puede apreciar cómo algunas de las más jóvenes investigadoras tendrían cabida dentro de la arqueología feminista. Una muestra sería la apuesta de Alejandra Sánchez Polo por el uso de vías alternativas al academicismo imperante, que se hace visible a través de su implicación en la Asociación de Jóvenes Historiadores, de Salamanca, y el recurso a publicar en revistas digitales recién creadas, como El Futuro del Pasado y Arkeogazte. A ello se une su creciente interés por la arqueología de la unidad doméstica. Otras licenciadas vienen apareciendo en los últimos años y, pese a que sus líneas de trabajo están aún poco definidas, muchas irán sumándose a esta corriente. Entre ellas estarían Cristina Tejedor Rodríguez, que ya ha empezado a dar muestras de su trabajo en las Jornadas de Jóvenes en Investigación Arqueológica (tanto en las celebradas en Madrid como en las de la
Asociación Zamora Protohistórica), Ana Herrero Corral (con su trabajo sobre la infancia durante el Calcolítico en el valle del Duero) y $\mathrm{M}^{\mathrm{a}}$ de los Reyes de Soto García. Así pues el presente apunta algunos cambios en esta tendencia, que podrán comprobarse en los próximos años.

\section{Agradecimientos}

Este escrito se ha desarrollado dentro del Grupo de Investigación HAR-2009-10105/HIST "Nuevos hallazgos y nuevas perspectivas en el estudio de los restos humanos de Cogotas I", que dirige Ángel Esparza Arroyo (Universidad de Salamanca). Además quisiera agradecer a Alejandra Sánchez Polo sus útiles e interesantes comentarios al borrador inicial de este trabajo.

\section{Bibliografía}

ABARQUERO MORAS, F. J. (2005): Cogotas I. La difusión de un tipo cerámico durante la Edad del Bronce. Monografías. Arqueología en Castilla y León 4. Valladolid.

ABARQUERO MORAS, F. J. (2012): “Cogotas I más allá del territorio nuclear. Viajes, bodas, banquetes y regalos en la Edad del Bronce peninsular". En J. A. Rodríguez Marcos y J. Fernández Manzano (eds.): Cogotas I. Una cultura de la Edad del Bronce en la Península Ibérica. Universidad de Valladolid, 59-110. Valladolid.

ABARQUERO MORAS, F. J. y GUERRA, E. (eds.) (2010): Los yacimientos de Villafáfila en el marco de las explotaciones salineras de la prehistoria europea. Junta de Castilla y León. Valladolid.

ABARQUERO, F. J. et al. (2010): "Excavaciones en los 'cocedreos' de sal prehistóricos de Molino Sanchón II y Santioste (Villafáfila, Zamora)". En F. J. Abarquero y E. Guerra (eds.): Los yacimientos de Villafáfila (Zamora) en el marco de las explotaciones salineras de la prehistoria europea. Junta de Castilla y León, 85-118. Valladolid.

ALARCÓN GARCÍA, E. (2007): "Las prácticas de cuidados en las sociedades prehistóricas: la Cultura Argárica”. Arqueología y Territorio 4, 233-249. 
BELLIDO BLANCO, A. (2004): Cambios sociales en la Prehistoria Reciente de la Meseta Norte: 5500-1000 AC. Tesis Doctoral inédita. Universidad de Valladolid.

BELLIDO BLANCO, A. (2008): "Primeros investigadores de la prehistoria vallisoletana". Sautuola XIV, 465-472. Santander.

BERROCAL, Ma C. (2009): "Feminismo, teoría y práctica de una arqueología científica". Trabajos de Prehistoria 66 (2), 25-43.

BLANCO GONZÁLEZ, A. (2005): “La cerámica de Cogotas I: nuevas respuestas a viejas preguntas". Zephyrus 58, 302-4.

BLANCO GONZÁLEZ, A. y PÉREZ ORTIZ, L. (2005): "El fenómeno orientalizante entre las comunidades del Primer Hierro del occidente de la cuenca del Duero". Anejos de Archivo Español de Arqueología XXXV, 1005-13.

BOSCH GIMPERA, P. (1923): El problema etnológico vasco y la Arqueología. Sociedad de Estudios Vascos, tomo XVI, núm. 4. San Sebastián.

BOURDIEU, P. (2009): Homo academicus. Siglo XXI editores. México.

BOURDIEU, P. (2012): Intelectuales, política y poder. Eudeba. Buenos Aires.

CABRÉ AGUILÓ, J. (1930): Excavaciones de Las Cogotas. Cardeñosa (Ávila). I. El Castro. Memorias de la Junta Superior de Excavaciones y Antigüedades, $\mathrm{n}^{\circ} 110$. Madrid.

CARDITO, L. M ${ }^{\mathrm{a}}$ et al. (1997): "Neolítico y arte rupestre en el Barranco del Duratón (Segovia)". II Congreso de Arqueología Peninsular (Zamora, 1996), 157-164. Zamora.

CELIS SÁNCHEZ, J. et al. (2007): “Consideración final: el depósito de Valdevimbre y la sociedad Cogotas I". En J. Celis et al. (eds.): El hallazgo leonés de Valdevimbre y los depósitos del Bronce Final Atlántico en la Península Ibérica. Estudios y Catálogos 17. Junta de Castilla y LeónDiputación de León, 168-175. Valladolid.

CHAPMAN, R. (2010): Arqueologías de la complejidad. Edicions Bellaterra. Barcelona.

COLOMER I SOLSONA, L. (2005): “Cerámica prehistórica y trabajo femenino en El Argar: una aproximación desde el estudio de la tecnología cerámica". En M. Sánchez Romero (ed.): Arqueología y género. Editorial Universidad de Granada, 177-217. Granada.
CONKEY, M. y TRINGHAM, R. (1995): "Archaeology and the Goddess: Exploring the contours of feminist archaeology". En D. C. Stanton y A. J. Steward (eds.): Feminist in the Academy. University of Michigan Press, 199247. Ann Arbor.

DELIBES DE CASTRO, G. (1977): El vaso campaniforme en la Meseta Norte española. Studia Archaeologica 46. Universidad de Valladolid.

DELIBES DE CASTRO, G. (1978): “Una inhumación triple de facies Cogotas I en San Román de la Hornija (Valladolid)". Trabajos de Prehistoria $35,225-250$

DELIBES, G., ALONSO, M. y ROJO, M. A. (1987): "Los sepulcros colectivos del Duero Medio y Las Loras, y su conexión, con el foco dolménico riojano". El megalitismo en la península ibérica, 181-197. Madrid.

DELIBES, G. y MUNICIO, L. (1981): “Apuntes para el estudio de la secuencia campaniforme en el oriente de la Meseta Norte". Numantia I, 65-82.

DELIBES, G. et al. (1990): "Cerámica de la plenitud Cogotas I: el yacimiento de San Román de Hornija (Valladolid)". Boletín del Seminario de Estudios de Arte y Arqueología LVI, 64-105.

DELIBES, G. et al. (1995): “¿La dote de una princesa irlandesa? A propósito de un torques áureo de la Edad del Bronce hallado en Castrojeriz (Burgos)". Homenaje al profesor Martín González, 51-61. Universidad de Valladolid.

DELIBES, G. et al. (1998): "Santioste, una factoría salinera de los inicios de la Edad del Bronce en Otero de Sariegos (Zamora)". En G. Delibes (coord.): Minerales y metales en la prehistoria reciente. Algunos testimonios de su explotación y laboreo en la península Ibérica. Studia Archaeologica 88, 155-197. Universidad de Valladolid.

DELIBES, G. et al. (2009): “Testimonios del consumo de cerveza durante la Edad del Cobre en la Tierra de Olmedo (Valladolid)". Castilla y el mundo feudal: homenaje al profesor Julio Valdeón, 585-599. Universidad de Valladolid.

DELIBES, G. y VAL RECIO, J. del (2007-08): “La explotación de la sal al término de la Edad del Cobre en la Meseta central española: ¿fuente de riqueza e instrumento de poder de los jefes Ciempozuelos?". Veleia 24-25 (2), 719-812. 
DELIBES, G. y ZAPATERO, P. (1995): "Sobre la implantación del megalitismo en el valle medio del Duero: el testimonio de La Velilla, en Osorno (Palencia)". Actas del III Congreso de Historia de Palencia, Tomo 1: Prehistoria, Arqueología e Historia Antigua, 35-63. Diputación Provincial de Palencia.

DÍAZ-ANDREU, M. (1998a): "Spanish women in a changing world. Strategies in the search for selffulfilment through antiquities". En M. DíazAndreu y M. L. S. Sorensen (eds.): Excavating Women. A History of Women in European Archaeology. Routledge, 125-145. Londres.

DÍAZ-ANDREU, M. (1998b): "Iberian post-palaeolithic art and gender: discussing human representations in Levantine art". Journal of Iberian Archaeology 0, 33-51.

DÍAZ-ANDREU, M. (2005): “.Gender identity”. En M. Díaz-Andreu, S. Lucy, S. Babic y D. Edwards (eds.): The Archaeology of Identity. Approaches to gender, age, status, ethnicity and religion. Routledge, 13-42. Londres.

DÍAZ-ANDREU, M. et al. (coords.) (2009): Diccionario Histórico de la Arqueología en España. Marcial Pons Historia. Madrid.

DÍAZ-GUARDAMINO URIBE, M. (1997): “El grupo megalítico de Villarmayor (Salamanca), contribución al estudio del Megalitismo del occidente de la Meseta Norte". Complutum 8, 39-56.

DÍAZ-GUARDAMINO, M. (2004): "Estelas antropomorfas y estatuas-menhir: su papel en la articulación del espacio funerario megalítico". Actas del VII Congreso Internacional de Estelas funerarias (Santander, octubre de 2002), vol. 1. Fundación Marcelino Botín, 111-121. Santander.

DÍAZ-GUARDAMINO, M. (2006): “Materialidad y acción social: el caso de las estelas decoradas y estatuas-menhir durante la Prehistoria peninsular". Actas do VIII Congresso Internacional de estelas funerarias (Museo Nacional de Arqueología, maio de 2005), O Arqueólogo Português, suplemento 3, 15-33.

DÍAZ-GUARDAMINO, M. (2008): “Iconical signs, indexical relations: Bronze Age stelae and statue-menhirs in the Iberian Peninsula". Journal of Iberian Archaeology 11, 31-45.

DÍAZ-GUARDAMINO, M. (2011): “Iconografía, lugares y relaciones sociales: Reflexiones en torno a las estelas y estatuas-menhir atribuidas ala Edad del bronce en la Península Ibérica”. En R. Vilaça (ed.): Estelas e Estátuas-menirES: da Pré à Proto-història (actas das IV Jornadas Raianas, Sabugal 2009). Câmara Municipal do Sabugal, 63-88.

DÍAZ-GUARDAMINO, M. (2012): "Estelas decoradas del Bronce Final en la Península Ibérica: datos para su articulación cronológica”. En J. Jiménez (ed.): Sidereum Ana II. El río Guadiana en el Bronce Final. Anejos del Archivo Español de Arqueología, 389-415.

ELIADE, M. (1974): Tratado de Historia de las religiones, vol. I. Ediciones Cristiandad. Madrid.

EIROA GARCÍA, J. J. (1979): La Cueva del Asno. Los Rábanos (Soria). Campañas 1976-1977. Excavaciones Arqueológicas en España 107. Ministerio de Cultura. Madrid.

ESCORIZA MATEU, T. (2002): La representación del cuerpo femenino. Mujeres y Arte Rupestre Levantino del arco mediterráneo de la Península Ibérica. Oxford.

ESCORIZA MATEU, T. (2006): "Mujeres, vida social y violencia. Política e ideología en el arte rupestre levantino". Cypsela 16, 19-36.

ESPARZA ARROYO, Á. (1990): "Sobre el ritual funerario de Cogotas I". Boletín del Seminario de Estudios de Arte y Arqueología 56, 106-143.

ESPARZA, A., VELASCO, J. y DELIBES, G. (2012a): "HUM 2005-00139: Planteamiento y primeros resultados de un proyecto de investigación sobre la muerte en Cogotas I". En J. A. Rodríguez Marcos y J. Fernández Manzano (eds.): Cogotas I. Una cultura de la Edad del Bronce en la Península Ibérica. Universidad de Valladolid, 259-320.

ESPARZA, A., VELASCO, J. y DELIBES, G. (2012B): "Exposición de cadáveres en el yacimiento de Tordillos (Aldeaseca de la Frontera, Salamanca). Perspectiva bioarqueológica y posibles implicaciones para el estudio del ritual funerario de Cogotas I". Zephyrus LXIX, 95-128.

FABIÁN GARCÍA, J. F. (2006): El IV y III Milenio AC en el Valle Amblés (Ávila), Monografías. Arqueología en Castilla y León, 5. Junta de Castilla y León.

FABIÁN GARCÍA, J. F. y BLANCO GONZÁLEZ, A. (2012): "Cuatro enterramientos calcolíticos en hoyo del Cerro de la Cabeza (Ávila)". Complutum 23 (1), 99-120. 
FÁBREGAS, R. y RUIZ-GÁLVEZ, M. (1997): “El Noroeste de la Península Ibérica en el III y II Milenios: propuestas para una síntesis". Saguntum (PLAV) 30, 191-216.

FAIRÉN, S. y GUERRA, E. (2005): “Paisaje y ritual: reflexiones sobre el contexto social del Arte Macroesquemático". Actas del Congreso de Arte Rupestre en la España Mediterránea (Alicante, octubre de 2003). Universidad de Cantabria, 705-714.

FERNÁNDEZ，J. J. (2005); “Ursicina Martínez Gallego (1906-2004). In memoriam". Мuseo 10, 363-365.

FERNÁNDEZ MANZANO, J. (1986): Bronce Final en la Meseta Norte española: el utillaje metálico. Monografías, Investigaciones Arqueológicas en Castilla y León.

FERNÁNDEZ MANZANO, J. y NEIRA CAMPOS, A. (2006-07): "Bronces prehistóricos en el municipio de Carrocera (León). Su interpretación desde la arqueología del paisaje". Lancia 7, 145-56.

FERNÁNDEZ-POSSE, Ma D. (1979): “Informe de la primera campaña (1977) en la cueva de Arevalillo (Segovia)". Noticiario Arqueológico Hispano 6, 51-87.

FERNÁNDEZ-POSSE, Ma D. (1981): "La cueva de Arevalillo de Cega (Segovia)". Noticiario Arqueológico Hispano 12, 43-84.

FERNÁNDEZ-POSSE， $\mathrm{M}^{\mathrm{a}} \quad$ D. (1982): "Consideraciones sobre la técnica de Boquique". Trabajos de Prehistoria 39, 137-159.

FERNÁNDEZ-POSSE, Ma D. (1986): "La cultura de Cogotas I'. Actas del Congreso 'Homenaje a Luis Siret (1934-1984)’, 475-487. Sevilla.

FERNÁNDEZ-POSSE, Mª D. (1986-87): “La cerámica decorada de Cogotas I". Zephyrus 39-40, 231-237

FERNÁNDEZ-POSSE, Ma D. (1998): La investigación protohistórica en la Meseta y Galicia. Editorial Síntesis. Madrid.

FERNÁNDEZ-POSSE, Mª D. (1999): "Marisa RuizGálvez Priego. La Europa Atlántica en la Edad del Bronce...". Trabajos de Prehistoria 56 (2), 197-199.

FERNÁNDEZ-POSSE, Ma D. (2000): "La mujer en la cultura castreña Astur". Arqueología Espacial 22, 143-60.
FUERTES PRIETO, M ${ }^{\mathrm{a}}$ N. y PÉREZ ORTIZ, L. (2008): "Material lítico tallado y pulimentado de yacimientos de la Edad del Hierro de la meseta oriental leonesa: la comarca de Los Oteros", Férvedes 5, 247-256.

GARCÍA BARRIOS, A. S. (2007); "Un enfoque de género en la Arqueología de la Prehistoria Reciente del valle medio del Duero: los cráneos femeninos calcolíticos de Los Cercados (Mucientes, Valladolid)". En C. de la Rosa Cubo et alii (coords.): Nuevos enfoques para la enseñanza de la Historia: mujer y género ante el Espacio Europeo de Educación Superior. Asociación Cultural Al-Mudayna, 41-56.

GARRIDO PENA, R. (2000): El campaniforme en la Meseta Central de la Península Ibérica (c. 25002000 BC). British Archaeological Reports. Oxford.

GILMAN, A. (2007): "Notas sobre la trayectoria científica de $\mathrm{M}^{\mathrm{a}}$ Dolores Fernández-Posse". Trabajos de Prehistoria 62 (2), 11-19.

GIMBUTAS, M. (1991): Dioses y diosas de la vieja Europa: 7000-3500 a. C. Istmo. Madrid.

GODELIER, M. (2005): La producción de Grande hombres. Poder y dominación masculina entre los Baruya de Nueva Guinea. Akal. Madrid.

GÓMEZ BARRERA, J. A. (1992): Grabados rupestres postpaleolíticos del Alto Duero. Museo Numantino-Caja Salamanca y Soria. Soria.

GÓMEZ BARRERA, J. A. (2001): Ensayos sobre el significado y la interpretación de las pinturas rupestres de Valonsadero. Diputación Provincial de Soria.

GONZÁLEZ FERNÁNDEZ, Mª L. (coord.) (2009): 'El Pelambre', Villaornate, León: el horizonte Cogotas I de la Edad del Bronce y el periodo tardoantiguo en el valle medio del Esla. Tragsa.

GONZÁLEZ MARCÉN, P, MONTÓN SUBÍAS, S. y PICAZO GURINA, M. (2007): "Continuidad y cambio social en la cultura material de la vida cotidiana". Complutum 18, 175-184.

GONZÁLEZ-MARCÉN, P. et al. (2008): "Engendering social dynamics. The archaeology of maintenance activities. An introduction". En S. Montón Subías y M. Sánchez-Romero (eds.): Engendering social dynamics: the archaeology of maintenance activities. BAR International series 1862, 1-2. 
GUERRA DOCE, E. (2002): "Sobre el papel de la adormidera como posible viático en el ritual funerario de la Prehistoria Reciente peninsular". Boletín del Seminario de Estudios de Arte y Arqueología 68, 49-76

GUERRA DOCE, E. (2005): "Reflexiones sobre el consumo de drogas en Europa durante la Edad del Bronce y la Edad del Hierro". En A. Blanco et al. (eds.): Bronce Final y Edad del Hierro en la Península Ibérica. Universidad de Salamanca, 131-141.

GUERRA DOCE, E. (2006a): Las drogas en la Prehistoria. Evidencias arqueológicas del consumo de sustancias psicoactivas en Europa. Bellaterra Arqueología. Barcelona.

GUERRA DOCE, E. (2006b): “Sobre la función y el significado de la cerámica campaniforme a la luz de los análisis de contenidos". Trabajos de Prehistoria 63 (1), 69-84.

GUERRA, E. y DELIBES, G. (2004): “Contexto y posible significado de un cuenco Ciempozuelos con decoración simbólica de ciervos hallado en Almenara de Adaja (Valladolid)". Zona Arqueológica 4, 116-125.

GUERRA DOCE, E. et al. (2009): "Primus inter pares: estrategias de diferenciación social en los sepulcros megalíticos de las Submeseta Norte española”. BSAA Arqueología LXXV, 41-65.

HERNÁNDO GONZÁLO, A. (2002): Arqueología de la identidad. Akal. Madrid.

JIMENO MARTÍNEZ, J. (1984): Los Tolmos de Caracena (Soria) (campañas de 1977, 1978 y 1979). Excavaciones Arqueológicas en España 134. Madrid.

JIMENO, A., FERNÁNDEZ, J. J. y REVILLA, Mª L. (1988): "Asentamientos de la Edad del Bronce en la provincia de Soria: consideraciones sobre los contextos culturales del Bronce Antiguo". Noticiario Arqueológico Hispano 30, 83-118.

LEISNER, V. y SCHUBART, H. (1964): “Dólmenes de Ciudad Rodrigo". Zephyrus 15, 47-59.

LÓPEZ PLAZA, S. (1975): "Morillos y objetos de culto de la Edad del Bronce hallados en Muñogalindo (Ávila)”. Crónica del XIII Congreso Nacional de Arqueología, 499-506. Zaragoza.

LÓPEZ PLAZA, S. (1979): “Aportación al conocimiento de los poblados eneolíticos del SO. De la Meseta N. española: la cerámica”. Setubal Arqueológica V, 67-102
LÓPEZ PLAZA, S. (1983): "Grabados rupestres esquemáticos en Muñogalindo (Ávila)”. Zephyrus 36, 203-207.

LÓPEZ, S. (1999): “Asociación de grabados de 'cazoletas' con el megalitismo salmantino". Zephyrus 52, 297-302.

LÓPEZ, S. y SANTOS, J. (1984-85): “Alabarda y puñales de lengüeta y remaches procedentes del S.O. de la cuenca del Duero". Zephyrus 37-38, 255-266.

LÓPEZ, S. et al. (1991-92): “Aplicación de la astronomía en el estudio de la orientación de sepulcros megalíticos de corredor en la zona noroccidental de la Península Ibérica". Zephyrus 44-45, 183-192.

LÓPEZ, S. et al. (2000): "Megalitismo y vías naturales de comunicación en el SO salmantino". $3^{\circ}$ Congresso de Arqueologia Peninsular: Utad, Vila Real, Portugal, setembro de 1999, vol. 3, 271-288. Porto.

LÓPEZ, S. et al. (2008): "Los factores litológicos como indicadores del paisaje en el megalitismo de la penillanura salmantina (centro-oeste de España)". Zephyrus 61, 107-130.

LUCAS DE VIÑAS, Ma R. (1971): "Pinturas rupestres del Solapo del Águila”. Trabajos de Prehistoria 28, 119-152

LUCAS PELLICER, $M^{\mathrm{a}}$ R. (1974): "El arte rupestre en la provincia de Segovia". Cuadernos de Prehistoria y Arqueología 1, 57-69.

LUCAS PELLICER, Ma R. (1975): "La pintura rupestre esquemática del barranco del río Duratón, Segovia”. Cuadernos de Prehistoria y Arqueología 2, 69-74

LUCAS PELLICER, Ma R. (1981): “Aproximación al conocimiento de las estaciones rupestres y de la pintura esquemática en el barranco del Duratón (Segovia)". Altamira Symposium (Madrid, 1979), 505-526. Madrid.

LUCAS PELLICER, M ${ }^{\mathrm{a}}$ R. (1989): “El horizonte de Cogotas I en San frutos del Duratón (Burgomillodo, Segovia)". Crónica del XIX Congreso Nacional de Arqueología (Valencia, 1987), 477-492. Zaragoza.

LUCAS PELLICER, Ma R. (1990): “El Santuario Rupestre del Solapo del Águila (Villaseca, Segovia) y el barranco sagrado del Duratón". Zephyrus 43, 199-208. 
LUCAS PELLICER, Ma R. (1992): “La pintura esquemática de las provincia de Soria y Segovia: estudio comparativo". II Symposium de Arqueología Soriana (19-21 de octubre de 1989), 261-278. Soria.

LUCAS PELLICER, M ${ }^{\mathrm{a}}$ R. (1995): "Mundo ritual y religioso: problemática". En Víctor Hurtado (dir.): El Calcolítico a debate: Reunión de Calcolítico de la Península Ibérica (Sevilla 1990). Sevilla, 117-121.

LUCAS, M a R. y CASTELO, R. (1992): "Los grabados rupestres de Soria y Segovia”. II Symposium de Arqueología Soriana (19-21 de octubre de 1989), 279-294. Soria.

MALUQUER DE MOTES, J. (1960): “Bases para el estudio de las culturas metalúrgicas de la Meseta". Ier Symposium de Prehistoria de la Península Ibérica (septiembre de 1959), 125150. Pamplona.

MARTÍN VALLS, R. y DELIBES, G. (1989): La cultura del vaso campanifome en las campiñas meridionales del Duero. El enterramiento de Fuente-Olmedo (Valladolid). Monografías del Museo Arqueológico de Valladolid, vol. 1.

MATÍAS RODRÍGUEZ, R. et al. (2003): "Explotación prehistórica del yacimiento de cobre de la mina La Profunda (Cármenes, León, España)". En J. M ${ }^{\mathrm{a}}$ Mara Perelló y J. R. González (coord..): Libro de actas del Primer Simposio sobre la Minería y la Metalurgia Antiua en el Sudoeste Europeo (Segría, Cataluña, mayo de 2000). Centre d'Arqueologia d'Avinganya, 117-32.

MEDEROS MARTÍN, A. (1995): “¿Retorno al pasado? Comercio o difusión en los análisis de los Sistemas Mundiales antiguos". Trabajos de Prehistoria 52, n 2, 131-141.

MERGELINA, C. de (1932-33): "Plan de trabajos del Seminario de Estudios de Arte y Arqueología para el presente curso". Boletín del Seminario de Estudios de Arte y Arqueología I, 9-11.

MERGELINA, C. de (1933-34): "Plan de trabajos del Seminario de Estudios de Arte y Arqueología para el presente curso". Boletín del Seminario de Estudios de Arte y Arqueología II, 3-6.

MÍNGUEZ ÁLVARO, M ${ }^{\mathrm{a}}$ T. (2005a): Estudio sobre Atapuerca (Burgos): III: Los materiales del Bronce Final de 'El Portalón' de Cueva Mayor. Universidad de Deusto-Diputación Provincial de Burgos.
MÍNGUEZ ÁLVARO, M M T. (2005b): “La cerámica de Boquique de 'El Portalón' de Cueva Mayor (Atapuerca). Propuesta experimental para la reconstrucción de la ejecución de la técnica". En M. Santonja et al. (eds.): Geoarqueología y Patrimonio en la Península Ibérica y el entorno mediterráneo. ADEMA, 507-16. Soria.

MOLINA, F. y ARTEAGA, O. (1976): "Problemática y diferenciación en grupos de la cerámica con decoración excisa en la Península Ibérica". Cuadernos de Prehistoria de la Universidad de Granada 1, 175-214.

MONTÓN SUBÍAS, S. (2010): "Muerte e identidad femenina en el mundo argárico". Trabajos de Prehistoria 67 (1), 119-137.

MONTÓN SUBÍAS, S. (2012): "Muerte y género en la Prehistoria española". En L. Prados Torreira (ed.): La Arqueología funeraria desde una perspectiva de género. UAM Ediciones, 21-37.

NARANJO GONZÁLEZ, C. (1984): "El Castillo de Cardeñosa. Un yacimiento de los inicios de la Edad del Bronce en la sierra de Ávila (excavaciones realizadas por J. Cabré en 1931)". Noticiario Arqueológico Hispano 19, 35-84.

NEIRA CAMPOS, A. et al. (2007): "La más antigua minería metálica en tierras de León”. En J. Celis (coord.): El hallazgo leonés de Valdevimbre y los depósitos del Bronce Final Atlántico en la Península Ibérica. Junta de Castilla y León, 22037.

ORTEGO FRÍAS, T. (1951): "Las estaciones de arte rupestre en el Monte Valonsadero de Soria". Celtiberia 2, 275-305.

ORTEGO FRÍAS, T. (1956): "Los grabados prehistóricos de la Cueva de Santa Cruz, en el término de Conquezuela (Soria)". Celtiberia 7, 131-138.

PÉREZ ORTIZ, L. (2005): “Nuevas aportaciones al estudio de la Primera Edad del Hierro en la meseta leonesa". En A. Blanco et al. (eds.): Bronce Final y Edad del Hierro en la Península Ibérica. Universidad de Salamanca, 251-275.

PERICOT GARCÍA, L. (1923): La Prehistoria de la Península Ibérica. Barcelona.

PERICOT GARCÍA, L. (1950): La España Primitiva. Barcelona.

PRADOS TORREIRA, L. (2012): "Prólogo". En L. Prados Torreira (ed.): La Arqueología funeraria desde una perspectiva de género. UAM Ediciones, 7-20. 
RODRÍGUEZ MARCOS, J. A. (2008): Estudio secuencial de la Edad del Bronce en la ribera del Duero (provincia de Valladolid). Junta de Castilla y León.

ROMÁN ROMÁN, A. y ALCAIN PARTEARROYO,

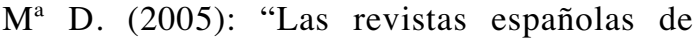
Prehistoria y Arqueología en el entorno de un sistema de valoración integrada”. Trabajos de Prehistoria 62 (2). Madrid, 7-23.

RUIZ-GÁLVEZ PRIEGO, M. (1987): “Bronce Atlántico y 'cultura' del Bronce Atlántico en la Península Ibérica”. Trabajos de Prehistoria 44, 251-64.

RUIZ-GÁLVEZ PRIEGO, M. (1992): “La novia vendida: orfebrería, herencia y agricultura en la Protohistoria de la Península Ibérica". SPAL 1, 219-252.

RUIZ-GÁLVEZ PRIEGO, M. (1995): “El significado de la Ría de Huelva en el contexto de las relaciones de intercambio y de las transformaciones producidas en la transición Bronce Final/Edad del Hierro". En M. Ruiz-Gálvez (ed.): Ritos de paso y puntos de paso: La ría de Huelva en el mundo del Bronce Final Europeo. Complutum, Extra 5, 129-155.

RUIZ-GÁLVEZ PRIEGO, M. (1998): La Europa Atlántica en la Edad del Bronce. Un viaje a las raíces de la Europa occidental. Crítica. Barcelona.

SAMANIEGO BORDIU, B. (1999): "Espacios simbólicos en el Bronce Antiguo del Alto Duero". Complutum 10, 47-79

SAMANIEGO BORDIU, B. (2003): "Cueva Maja en 'Expresiones del Límite'”. Complutum 14, 434444.

SAMANIEGO, B. et al. (2002): Cueva Maja (Cabrejas del Pinar, Soria): espacio y simbolismo en los inicios de la Edad del Bronce. Junta de Castilla y León. Valladolid.

SANAHUJA YLL, M ${ }^{\mathrm{a}}$ E. (2007): “¿Armas o herramientas prehistóricas? El ejemplo del mundo argárico". Complutum 18, 195-200.

SÁNCHEZ LIRANZO, O. (2005): "La investigación prehistórica en Andalucía occidental. Un estudio historiográfico". En M. Sánchez Romero (ed.): Arqueología y género. Editorial Universidad de Granada, 457-477.
SÁNCHEZ LIRANZO, O. (2008); "El debate teórico en los estudios de la arqueología del género y su incidencia en la Prehistoria". En L. Prados Torreira y C. Ruiz López (eds.): Arqueología del género. 1er Encuentro Internacional en la UAM. UAM Ediciones, 43-60.

SÁNCHEZ POLO, A. (2010): "La muerte en la Arqueología: visiones cruzadas / posiciones encontradas". El Futuro del Pasado. Revista electrónica de Historia 1, 173-187.

SÁNCHEZ POLO, A. (2011): “Aproximación espacial a una composición decorativa en cerámicas de Cogotas I". Actas del I Congreso de Chamartín (Ávila). Ávila, 105-115.

SÁNCHEZ POLO, A. (2012a): "Algo más que animales de compañía: la deposición ritualizada de perros en hoyos en el solar de Cogotas I". En J. A. Rodríguez y J. Fernández (eds.): Cogotas I: una cultura de la Edad del Bronce en la Península Ibérica (Valladolid, 19-22 de octubre de 2009). Universidad de Valladolid, 449-468.

SÁNCHEZ POLO, A. (2012b): "Depósitos de cerámicas, molinos y elementos de hoz: una propuesta de la Edad del Bronce del interior peninsular desde la arqueología posprocesual". Arkeogazte 2, 73-93.

SÁNCHEZ ROMERO, M. (ed.) (2005): Arqueología y género. Editorial Universidad de Granada.

SÁNCHEZ ROMERO, M. (2008): "Cuerpos de mujeres: la construcción de la identidad y su manifestación durante la Edad del Bronce". Arenal 15(1), 5-29.

SÁNCHEZ ROMERO, M. (2009): "Women in Bronze Age southeast Iberian península: faily life, relationships, identities". En K. Kopala (ed.): Fylo. Engendering Prehistoric 'Stratigraphies' in the Aegean and the Mediterranean (Proceedings of an International Conference, University of Crete, 2-5 June 2005). Aegaeum 30, 75-79.

SÁNCHEZ ROMERO, M. y ARANDA JIMÉNEZ, G. (2005): "El cambio en las actividades de mantenimiento durante la Edad del Bronce: nuevas formas de preparación, presentación y consumo de alimentos". Treballs d'Arqueologia 11, 73-91

SÁNCHEZ ROMERO, M., ARANDA JIMÉNEZ, G. y ALARCÓN GARCÍA, E. (2007): “Gender and age identities in rituals of comensality. The argaric societies", Treballs d'Arqueologia 13, 69-89. 
SENNA-MARTÍNEZ, J. C. et al. (1997): “Territorio, ideología y cultura material en el Megalitismo de la Plataforma del Mondego (centro de Portugal)". O neolítico atlántico e as orixes do megalitismo: actas do Coloquio Internacional (Santiago de Compostela, 1-6 de abril de 1996), 657-676. Santiago de Compostela.

SEVILLANO SAN JOSÉ, M M $^{\mathrm{a}}$ C. (1991): "Conexiones de las estelas antropomorfas salmantinas y extremeñas. Análisis de nuevos datos para su estudio en la provincia de Salamanca". En M. Santonja (coord.): Del Paleolítico a la Historia. Junta de Castilla y León-Museo de Salamanca, 99-116. Salamanca.

SEVILLANO, M ${ }^{\mathrm{a}}$ C. et al. (1996): "Estatua-menhir de Tremedal de Tormes (Salamanca)". Zephyrus 49, 295-303.

SHERRATT, A. (1993): "What would a Bronze-Age World System look like? Relations between temperate Europe and the Mediterranean in Later Prehistory”. Journal of European Archaeology 2 (1), 1-56.
TARACENA AGUIRRE, B. (1927): Excavaciones en las provincias de Soria y Logroño: memoria de las excavaciones practicadas en 1925-26. Junta Superior de Excavaciones y Antigüedades. Madrid.

VV. AA. (2008): de Amiticia, homenaje a Carmen Trapote. Diputación de Palencia.

WATTENBERG GARCÍA, E. (2000): De la galería arqueológica al Museo de Valladolid (18752000). Real Academia de Bellas Artes de la Purísima Concepción de Valladolid. Valladolid

WATTENBERG SAMPERE, F. (1949): "Prospecciones arqueológicas en el área de Villabrágima (provincia de Valladolid)". Boletín del Seminario de Estudios de Arte y Arqueología XV, 201-209. 
